\title{
Nanofluids Characterization for Spray Cooling Applications
}

\author{
Miguel Sanches ${ }^{1}$, Guido Marseglia ${ }^{2,3, *}$, Ana P. C. Ribeiro ${ }^{4, *}$, António L. N. Moreira ${ }^{1}$ (D) and Ana S. Moita ${ }^{1,5, * \mathbb{C}}$ \\ 1 IN+ Center for Innovation, Technology and Policy Research, Instituto Superior Técnico, \\ Universidade de Lisboa, 1049-001 Lisboa, Portugal; miguel.sanches@tecnico.ulisboa.pt (M.S.); \\ aluismoreira@tecnico.ulisboa.pt (A.L.N.M.) \\ 2 Escuela Técnica Superior de Arquitectura de Sevilla, Av. de la Reina Mercedes, 2, 41012 Seville, Spain \\ 3 Instituto de Matemáticas de la Universidad de Sevilla, (IMUS), Universidad de Sevilla, 41012 Seville, Spain \\ 4 Centro de Química Estrutural, Instituto Superior Técnico, Universidade de Lisboa, 1049-001 Lisbon, Portugal \\ 5 CINAMIL—Military Academy Research Center, Portuguese Military Academy, 1169-203 Lisbon, Portugal \\ * Correspondence: marseglia@us.es (G.M.); apribeiro@tecnico.ulisboa.pt (A.P.C.R.); \\ anamoita@tecnico.ulisboa.pt (A.S.M.)
}

Citation: Sanches, M.; Marseglia, G.; Ribeiro, A.P.C.; Moreira, A.L.N.; Moita, A.S. Nanofluids Characterization for Spray Cooling Applications. Symmetry 2021, 13, 788. https://doi.org/10.3390/sym13050788

Academic Editor: Denis A. Vinnik

Received: 8 April 2021

Accepted: 29 April 2021

Published: 2 May 2021

Publisher's Note: MDPI stays neutral with regard to jurisdictional claims in published maps and institutional affiliations.

Copyright: (C) 2021 by the authors. Licensee MDPI, Basel, Switzerland. This article is an open access article distributed under the terms and conditions of the Creative Commons Attribution (CC BY) license (https:// creativecommons.org/licenses/by/ $4.0 /)$.

\begin{abstract}
In this paper the mathematical and physical correlation between fundamental thermophysical properties of materials, with their structure, for nanofluid thermal performance in spray cooling applications is presented. The present work aims at clarifying the nanofluid characteristics, especially the geometry of their nanoparticles, leading to heat transfer enhancement at low particle concentration. The base fluid considered is distilled water with the surfactant cetyltrimethylammonium bromide (CTAB). Alumina and silver are used as nanoparticles. A systematic analysis addresses the effect of nanoparticles concentration and shape in spray hydrodynamics and heat transfer. Spray dynamics is mainly characterized using phase Doppler interferometry. Then, an extensive processing procedure is performed to thermal and spacetime symmetry images obtained with a high-speed thermographic camera to analyze the spray impact on a heated, smooth stainless-steel foil. There is some effect on the nanoparticles' shape, which is nevertheless minor when compared to the effect of the nanoparticles concentration and to the change in the fluid properties caused by the addition of the surfactant. Hence, increasing the nanoparticles concentration results in lower surface temperatures and high removed heat fluxes. In terms of the effect of the resulting thermophysical properties, increasing the nanofluids concentration resulted in the increase in the thermal conductivity and dynamic viscosity of the nanofluids, which in turn led to a decrease in the heat transfer coefficients. On the other hand, nanofluids specific heat capacity is increased which correlates positively with the spray cooling capacity. The analysis of the parameters that determine the structure, evolution, physics and both spatial and temporal symmetry of the spray is interesting and fundamental to shed light to the fact that only knowledge based in experimental data can guarantee a correct setting of the model numbers.
\end{abstract}

Keywords: nanofluids; thermal performance; cooling; heat transfer; infrared thermography; spacetime symmetry images

\section{Introduction}

The dissipation of high thermal loads is still an obstacle to overcome in several applications such as in electronics cooling, UAV's (for military applications), among others [1].

In this context, spray cooling is pointed as a high potential solution. In most spray characterization processes, the analysis of physical processes involved are fundamental. In order to reduce some computational times for different numerical codes and also in the experimental image treatment analysis, the detailed study of some geometrical parameters as the symmetric behavior of the jet is considered fundamental. However, further improvements are still addressed, for instance towards the use of nanofluids

Nanofluids are composed of a basic fluid to which nanometer particles (of sizes up to $100 \mathrm{~nm}$ ) of several materials such as metals (and metal oxides) are added [2-4]. Nanofluids 
have been extensively used in several flow geometries [5-9], but still not much explored in spray cooling systems. Saxena et al. [10] used a mixture of $\mathrm{TiO}_{2}$ nanoparticles with fuels for diesel engines obtaining thermal and environmental benefits. Kulkarni et al. [11] studied the effect of the use of nanoparticles in the thermophysical properties (viscosity) and convective thermal behavior in nanofluids utilized for heating buildings in cold zones. Their results demonstrated an increase of the heat flux exchange for higher percentages of nanoparticles (considering the range between the $0 \%$ and the $6 \%$ ).

Bansal and Pyrtle [12] analyzed the potential of the use of nanofluids in spray cooling processes, considering alumina nanoparticles added to water. Wang and $\mathrm{Xu}$ [13] report the improvement of the cooling process, with the use of alumina nanofluids.

In spray cooling applications, the main emphasis is put in the analysis of the bulk thermal properties that are related to the removed heat fluxes. However, spray cooling is a highly complex process from the hydrodynamic point of view, so that effects of the nanoparticles in the wettability atomization and droplet-droplet and droplet-surface interactions are also relevant to understand [14-18]. Various methodologies of optical diagnosis are actually employed in atomization features of the fluid to acquire key parameters such as the droplet size or the Sauter Mean Diameter (SMD). One of these is based on the Phase Doppler Interferometry (PDI) equipment. Dodge et al. [19] considered the PDI instrument to obtain the experimental droplets size measurement. Additionally, Stapleton et al. [20], Taylor et al. [21] and Clifford et al. [22] used the PDI methodology to investigate the spray nebulization evolution. Corcoran et al. [23] analyzed the droplets size in biomedical nebulizer spray fields.

Hwang et al. [24] employed the PDI system in order to evaluate the Sauter Mean Diameter (SMD) for engine fuel characterization. In their study, they developed an experimental comparison between the viscosity, the surface tension, the density and the spray break-up of the biodiesel fuel considered and the conventional diesel fuel. The air-fuel ratio of the engine charge was also considered.

Based on the PDI utilization, also Kay et al. [25] detected a series of experimental high spatio-temporal images in order to analyze into detail the spray droplets evolution after and before the impingement event. The aim of this research is to carry out and analyze the experimental tests needed to deepen the knowledge of the behavior of nanofluids in cooling processes, and of the main physical properties of nanofluids, considering different percentages of nanoparticles. The main innovative aspects are the use of the PDI technique, coupled with an Infrared Analysis and the kind of percentages of nanoparticles considered to examine the effects in heat exchange and wetting surface processes.

In this context, the present work combines the use of the PDI with time resolved thermographic analysis to obtain a full relation between the spray hydrodynamics and the heat transfer mechanisms at spray impact. Firstly, spray dynamics are evaluated and quantified. Then, these data are used to predict the impact outcomes. Finally, all the information prior and during impact is related to the information obtained from spray footprints on a heated, smooth stainless-steel foil. The quantitative analysis addresses radial surface temperature profiles, heat fluxes and heat transfer coefficients. This analysis is used to quantify the effect of nanoparticles shape, material and concentration.

The aforementioned discussion rests on the analysis of different features of the different nanofluids generated and studied within this work, as well as its characterization and determination of the most important thermophysical properties for the validation of the results. The objective of the present study is to further investigate nanofluids and in this manner diminish the gap between experimental values and proposed models. Hence, the authors have attempted to improve the knowledge of these 2 nanofluids (due to their importance for several fields in chemistry and physics) and compare our conclusions with the scarce information reported in the literature. 


\section{Experimental Methodology}

\subsection{Experimental Set-Up}

Various nanofluids, composed by alumina and silver nanoparticles dispersed in DI water and $0.05 \mathrm{wt} \% \mathrm{CTAB}$ - cetyltrimethylammonium bromide - were atomized using a tangential pressure-swirl atomizer that creates a hollow cone shaped spray. A systematic study addressed the effect of the concentration of the nanoparticles, the material and their shape (in the silver nanofluids, spherical and triangular nanoparticles were compared) on the thermophysical properties of the nanofluids and on their consequent effects on the atomization and hydrodynamics of the sprays, as well as on the heat transfer at spray impact on a hot and smooth stainless-steel surface. Figure 1a depicts the experimental apparatus used in the present work. The atomizer was used and characterized in a previous work [26], and it has a discharge orifice of $0.42 \mathrm{~mm}$ in diameter and two opposing tangential inlet ports with a squared shape cross section of $0.6 \times 0.6 \mathrm{~mm}^{2}$.

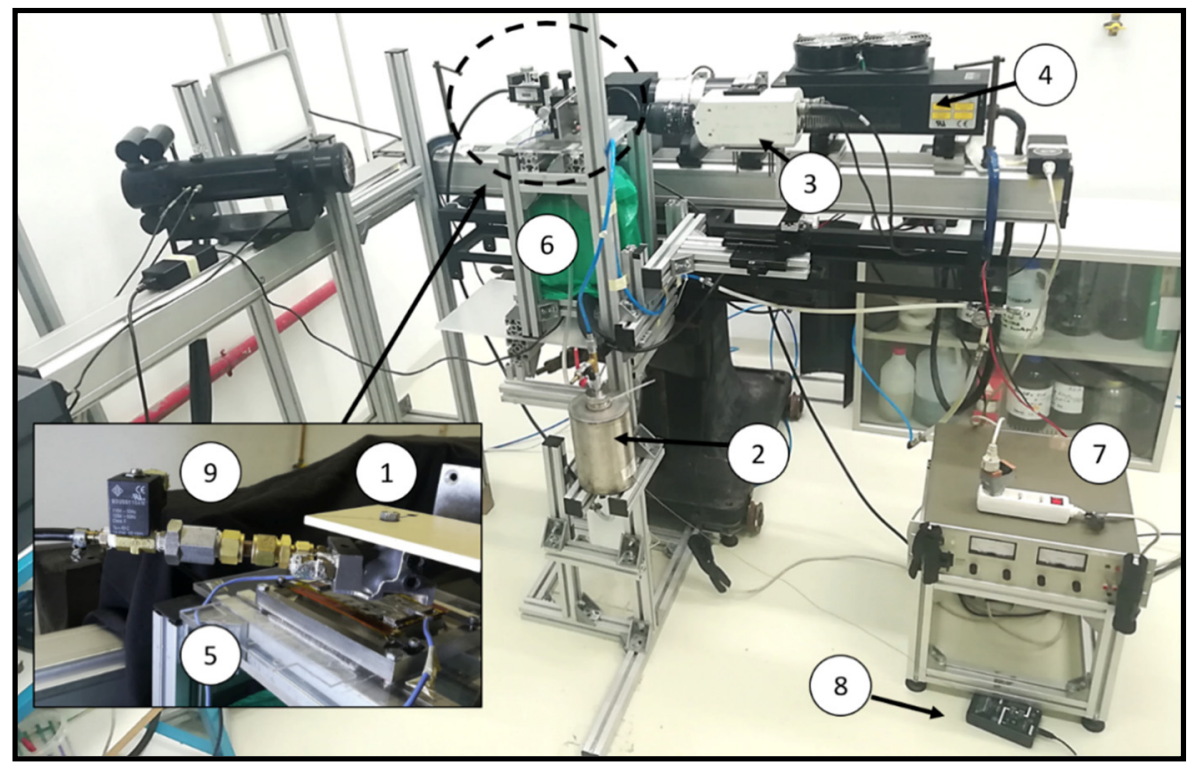

(a)

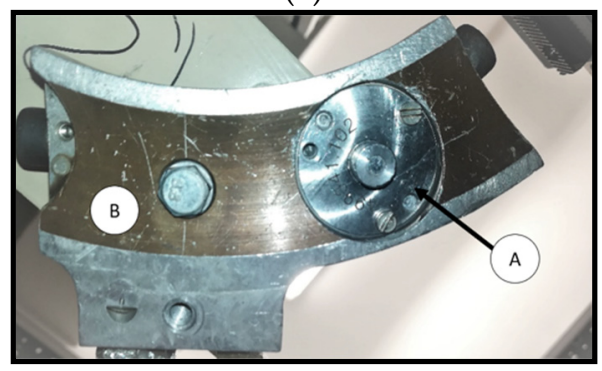

(b)

Figure 1. (a) Experimental setup scheme: (1) atomizer, (2) liter reservoir, (3) acquisition system, (4) Phase Doppler Anemometry system (5) steel support, (6) high-speed thermographic camera, (7) DC power supply, (8) data acquisition board and (9) solenoid valve. (b) Bench swirl atomizer.

As shown in Figure 1b, the atomizer (1) is composed by two main pieces: the swirl nozzle (A) and a distribution canal (B). The atomizer is connected to a support that allows its displacement in three axes. The incoming liquid is supplied from a $3 \mathrm{~L}$ reservoir (2), pressurized by air, coming from a compressor. After atomization, the liquid is collected by a tube connected to a vessel, due to gravity, and re-used afterwards. The spray was characterized with two different setup arrangements: one prior to impact analysis (I), and the other during spray impact (II). 
Setup (I) uses an image acquisition system to characterize the spray morphology. Then, droplets size and velocity distributions are quantitatively characterized by Phase Doppler Anemometry (PDA). The image acquisition system (3) is composed of a highspeed camera (Phantom v4.2, with $512 \times 512$ pixels at $2100 \mathrm{fps}$, with a maximum frame rate of 90,000 fps) that was connected to a computer so that one can control the filming characteristics, using its software. The illumination was provided by a $50 \mathrm{~W}$ diffusing spotlight, ensuring a homogenized background light. The Phase Doppler Anemometry (PDA) system is mainly composed of a particle and flow processor (DANTEC DYNAMICS BSA P80) and a 300-400 mW Ar-Ion laser from Spectra-Physics (4).

For setup (II), in order to analyze spray impact, a heated foil consisting of an AISI304 stainless steel sheet was used. This foil, with dimensions of $60 \mathrm{~mm} \times 90 \mathrm{~mm}$ and $20 \mathrm{~mm}$ thick is sustained by a steel support (5) that collects the hot liquid, redirecting it to a closed vessel, as depicted in Figure 1a. Regarding heat transfer analysis, a high-speed thermographic camera (Onca-MWIR-InSb from Xenics) (6), covered with a plastic bag to prevent water damage, was used to read the IR radiation emitted by the heated surface. The surface was heated by the Joule effect, using an HP6274B DC power supply (7) that imposes an adjustable continuous current. Moreover, the ambient temperature was monitored using a $\mathrm{K}$ type thermocouple, C03-K from OMEGA, controlled by a data acquisition board DT9828 from DATA TRANSLATION (8). Finally, the liquid discharge was controlled using a solenoid valve (SV3108 from OMEGA) (9) to ensure identical discharge actuation, in order to improve impact repeatability. The surface was characterized in terms of topography and wettability. Surface topography was characterized using a profilometer (a Dektak 3 from Veeco), with a vertical resolution of $20 \mathrm{~nm}$. The surface is perfectly smooth within this vertical resolution. The wettability was characterized based on the measurement of the equilibrium contact angle, with an optical tensiometer (THETA from Attention), using the sessile droplet method, as detailed for instance in [26]. The static contact angle $\mathrm{q}=86.5 \pm 6.4^{\circ}$ for water on the AISI304 stainless steel surface, measured at $20^{\circ} \mathrm{C} \pm 3{ }^{\circ} \mathrm{C}$. As the surfactant is added the contact angle decreases, as expected to $\mathrm{q}=53.6 \pm 6.3^{\circ}$. Then, the contact angle slightly decreases between $61.8 \pm 2.9^{\circ}<\mathrm{q}<57.9 \pm 11.3^{\circ}$ for the alumina nanofluids, as the alumina concentration increases from $0.5 \mathrm{wt} \%$ to $2 \%$. Regarding the silver nanofluids, $\mathrm{q}=51.1 \pm 3.5^{\circ}$ for the silver nanofluid with the spherical particles and $\mathrm{q}=47.3 \pm 6.3^{\circ}$ for the silver nanofluid with the triangular particles.

\subsection{Preparation and Characterization of the Nanofluids}

In the present work, nanofluid synthesis followed the procedure described in our previous study [26]. Within this research, efforts have been made to investigate the effects of nanoparticles addition on the thermo-physical properties, stability and heat transfer performance in spray cooling of hot steel plate. The nanofluids were prepared at the Structural Chemistry Center of the Department of Chemical Engineering at Instituto Superior Técnico of Lisbon. As aforementioned, the study addressed the effect of the concentration, material and shape of the nanoparticles. The effect of the concentration was focused on the alumina nanofluids, in which the nanoparticles concentration was varied between $0.5 \mathrm{wt} \%$ and $2 \mathrm{wt} \%$. Alumina and silver nanofluids were compared for the same nanoparticles concentration $(1 \mathrm{wt} \%)$ to infer on the effect of the nanoparticles material. Finally, spherical and triangular silver nanoparticles ( $1 \mathrm{wt} \%$ ) were used to investigate the effect of the shape of the nanoparticles. All the nanoparticles were dispersed in the same base fluid composed of distilled water and $0.05 \mathrm{wt} \% \mathrm{CTAB}$ - cetyltrimethylammonium. The fluids were characterized in terms of specific mass $\rho_{l}$, specific heat $C_{p l}$, thermal conductivity, $k_{l}$, surface tension $s_{l}$ and dynamic viscosity $\eta_{l}$.

The specific mass, $r_{l}$ of the nanofluids fluids was calculated as reported by Sharma et al. [27]:

$$
\rho_{l}=f_{n p}+\left(1-f_{n p}\right) \rho_{b f}
$$

where $\rho_{l}$ is the specific mass of the nanofluid, $\rho_{n p}$ is the specific mass of the nanoparticle and $\rho_{b f}$ is the specific mass of the base fluid. $f_{n p}$ is the volume fraction of the nanoparticles 
defined as $f_{n p}=m_{n p} /\left(m_{n p} / \rho_{n p}+m_{b f} / \rho_{b f}\right)$, being $m_{n p}$ the mass of the nanoparticles and $m_{b f}$ the mass of base fluid, respectively.

The specific heat capacity $C_{p l}$ was determining according to Equation (2):

$$
C_{p l}=\left(f_{n p}\left(\rho C_{p}\right)_{n p}+\left(1-f_{n p}\right)\left(\rho C_{p}\right)_{b f}\right) / \rho_{l}
$$

Thermal conductivity $k_{l}$, was determined from Equations (3) or (4), for the spherical or triangular shaped nanoparticles, respectively:

$$
\begin{gathered}
k_{l}=k_{b f} \frac{2 k_{b f}+k_{n p}+2 \varnothing_{n p}\left(k_{n p}-k_{b f}\right)}{2 k_{b f}+k_{n p}-\varnothing_{n p}\left(k_{n p}-k_{b f}\right)} \\
k_{l}=k_{b f} \frac{k_{n p}+(n-1) k_{b f}-(n-1) \varnothing_{n p}\left(k_{b f}-k_{n p}\right)}{k_{n p}+(n-1) k_{b f}+\varnothing_{n p}\left(k_{b f}-k_{n p}\right)}
\end{gathered}
$$

Here, $n$ is an empirical shape factor related to the particle sphericity. In our study, Equations (1)-(4) are fundamental for the optimal analysis and comprehension of complex phenomena involved in the link between the shape of the spray droplets and the thermophysical properties as the viscosity and the surface tension during the heat transfer mechanism.

Qi et al. [28] describe shape factor of a nanoparticle as the ratio of the surface area of the nanoparticle $S$ to that of an equivalent spherical nanoparticle with the same volume $S^{\prime \prime}$, thus $n=S / S^{\prime \prime}$. A complete knowledge of the physics-based analytical expression for the effective viscosity implementing theories from thermodynamics, considering the nanoparticle-fluid link, density effects, size effects and nanoparticle volume fraction is today the challenge of many investigations. Mcaffe [29] proposed a fundamental expression that considers the effect of the density ratio of the nanoparticles with respect to the fluid viscosity. He also demonstrated as the nanoparticle-fluid interactions become increasingly important for smaller nanoparticle sizes.

The dynamic viscosity, $\eta_{l}$ on the other hand, was experimentally measured at $20{ }^{\circ} \mathrm{C}$, using a TA instruments ARI 500 ex rheometer. The measurements have an accuracy of $\pm 5 \%$. Finally, the surface tension, $s_{l}$, was measured using the optical tensiometer THETA, from Attention. Fifteen measurements were performed for each fluid, at $20{ }^{\circ} \mathrm{C} \pm 3{ }^{\circ} \mathrm{C}$, using the pendant drop method. Detailed description of the procedure followed can be described in [26].

Table 1 summarizes the thermophysical properties of all the fluids studied in the

\begin{tabular}{|c|c|c|c|c|c|}
\hline Fluid Composition & $\rho_{l}\left[\mathrm{~kg} / \mathrm{m}^{3}\right]$ & $C_{p l}[\mathrm{~kJ} /(\mathrm{kg} \cdot \mathrm{K})]$ & $k_{l}[\mathbf{W} /(\mathbf{m} \cdot \mathbf{K})]$ & $s_{l}[\mathrm{mN} / \mathrm{m}]$ & $\eta_{l}[\mathrm{mPa} \cdot \mathrm{s}]$ \\
\hline Water & 998 & 4.22 & 0.6060 & $74.6 \pm 2.2$ & 1.009 \\
\hline Water $+0.05 \%(\mathrm{~m} / \mathrm{m}) \mathrm{CTAB}$ & 999 & - & - & $35.9 \pm 0.9$ & 1.291 \\
\hline Water $+0.05 \%(\mathrm{~m} / \mathrm{m})$ CTAB $+0.5 \%(\mathrm{~m} / \mathrm{m})$ Alumina & 1002 & 4.20 & 0.6082 & $39.0 \pm 1.3$ & 3.572 \\
\hline Water $+0.05 \%(\mathrm{~m} / \mathrm{m}) \mathrm{CTAB}+1 \%(\mathrm{~m} / \mathrm{m})$ Alumina & 1006 & 4.19 & 0.6104 & $40.2 \pm 2.7$ & 6.815 \\
\hline Water $+0.05 \%(\mathrm{~m} / \mathrm{m}) \mathrm{CTAB}+2 \%(\mathrm{~m} / \mathrm{m})$ Alumina & 1011 & 4.15 & 0.6149 & $40.2 \pm 0.9$ & 8.835 \\
\hline Water $+0.05 \%(\mathrm{~m} / \mathrm{m})$ CTAB $+1 \%(\mathrm{~m} / \mathrm{m})$ Silver (Spherical) & 1023 & 4.12 & 0.6106 & $40.0 \pm 0.4$ & 13.175 \\
\hline Water $+0.05 \%(\mathrm{~m} / \mathrm{m})$ CTAB $+1 \%(\mathrm{~m} / \mathrm{m})$ Silver (Triangular) & 1023 & 4.12 & 0.6096 & $43.1 \pm 0.4$ & 18.903 \\
\hline
\end{tabular}
present work.

Table 1. Thermophysical properties of the working fluids.

Stability of the Nanofluids

The stability of the nanofluids is a relevant issue, both for reproducibility of their thermophysical properties and for practical applications where, most of the time, durability and low maintenance of the systems is of paramount importance. Visual inspection of the nanofluids used in the present study signals that the silver nanofluids have very low stability, as the silver nanoparticles start to oxidize almost immediately. This oxidation leads to the formation of silver oxide, which starts to precipitate. This reaction is promoted 
when the nanofluid is stored in a place with strong light and heat. On the other hand, the alumina nanofluids, are chemically stable. Only gravitational precipitation of the particles is observed for time intervals at rest longer than $48 \mathrm{~h}$, but they can be reused after sonication.

\subsection{Measurement Techniques}

\subsubsection{Phase Droplet Anemometry Measurements}

Droplet size and velocity distributions were measured using a two-component Phase Doppler Anemometer. The optical configuration and validation parameters used with this system are summarized in Table 2. The burst signal processor P80 was used, combined with the BSA flow software v5.20. The parameters used in the software are a Photomultiplier sensitivity of 1180-1500 V, a Signal gain of 22-26 dB, a Center velocity of $15 \mathrm{~m} / \mathrm{s}$, a Velocity span of $30-40 \mathrm{~m} / \mathrm{s}$ and a Refractive index of 1.334 .

Table 2. Phase Doppler optical configuration and validation parameters.

\begin{tabular}{cc}
\hline & Value \\
\hline Transmitting optics & \\
Laser power [mW] & 400 \\
Laser wavelengths [nm] & 514 and 488 \\
Beam spacing [mm] & 60 \\
Frequency shift [MHz] & 40 \\
Transmitter focal length [mm] & 310 \\
Receiving optics & $69^{\circ}$ \\
Scattering angle [ ${ }^{\circ}$ ] & 500 \\
Receiver focal length [mm]
\end{tabular}

Measurements were made transverse to the control volume of the Phase Doppler system at $Z=10 \mathrm{~mm}$ and $Z=20 \mathrm{~mm}$ from the atomizer, which are correlated to the first and second atomization instances [8]. The measured points consist of a radial grid, where $r=0 \mathrm{~mm}$ corresponds to the radial origin of the spray axis. Initially, two sets of measurement grids were taken: $-20 \mathrm{~mm}<r<20 \mathrm{~mm}$ (for $Z=20 \mathrm{~mm}$ ) and $-12 \mathrm{~mm}<r<12 \mathrm{~mm}$ (for $Z=10 \mathrm{~mm}$ ) in $2 \mathrm{~mm}$ steps for two perpendicular axes, in order to evaluate spray symmetry and homogeneity, as showed in Figure 2. U and V stand for the axial and transverse velocity components, respectively. The radial grid was reduced, measuring the most relevant points in only one axis. This consisted of measurements at $r=[0,4,8,10,12$, $14,16,20]$ for $Z=20 \mathrm{~mm}$ and $r=[0,2,4,6,8,10,12]$ for $Z=10 \mathrm{~mm}$.

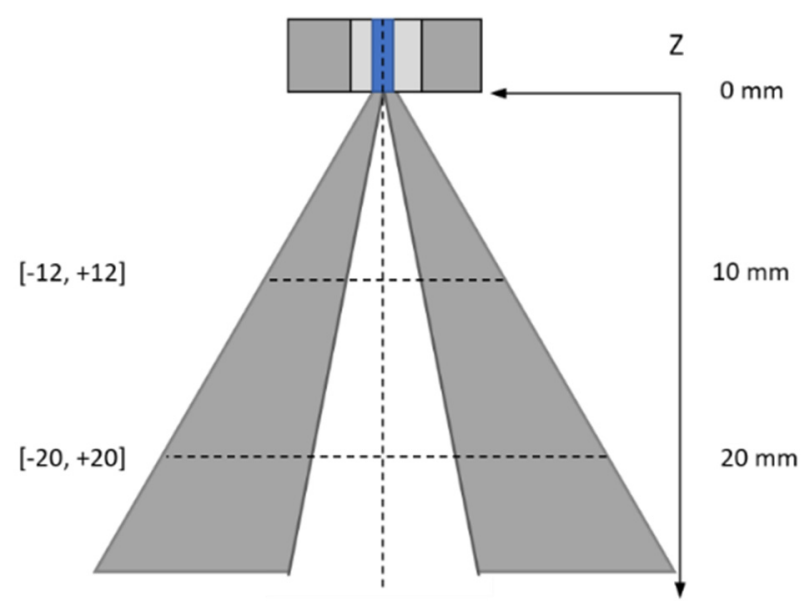

Figure 2. Measurement grid used for the phase Doppler Anemometry measurements. 
The number of measured samples for each grid point was divided in two regions, due to the hollow cone shape of the spray. Thus, measurements, for higher droplet concentration zones, were limited to 50,000 acquired, to guarantee measurement sample independence and to minimize errors due to sample inaccuracy, as 35,000 samples are the recommend samples to achieve 2\% accuracy for SMD (Sauter Mean Diameter) measurements. Lower droplet concentration regions were limited to 5000 samples, which despite being more sensitive to inaccuracy errors, according to [26], it is considered to be a "reasonably accurate" sample size. Droplet size and velocity distributions were obtained following the description procedures defined in previous work [26].

2.3.2. Time Resolved Thermography: Heat Transfer Analysis upon Spray Impact on the Heated Surface

After measuring the temperature of the fluid to be tested, the fluid was placed inside the high-pressure vessel. The nozzle height relative to the foil was adjusted as necessary. Then, the compressed air valve was opened to pressurize the vessel. A thermographic video with 5 frames of the foil before heating was recorded at $40 \mathrm{fps}$ and with a resolution of $320 \times 256$ pixels. The size of the pixel in the thermographic camera is $222 \mu \mathrm{m} /$ pixel. Thereafter, the power source was turned on and set to the desired current. While the foil temperature increased, the ambient temperature and the difference of electric potential between the contacts were checked using a multimeter and registered. Once the temperature of the foil has stabilized, the thermographic and high-speed recordings were initiated. The solenoid valve was only opened once the thermographic camera recording rate has stabilized. When the recordings finished, the surface was cleaned using acetone and distilled water. For each experimental condition, three identical tests were performed in a row. When changing the test fluid, all wet parts were cleaned with distilled water and dried.

As aforementioned, the foil was heated by Joule, imposing two currents, $(I=10 \mathrm{~A}$ and $I=15 \mathrm{~A}$ ), which correspond to the imposed heat fluxes $q_{\text {Joule }}=914.5 \mathrm{~W}$ (and an initial temperature of $T_{0}=84.14{ }^{\circ} \mathrm{C}$ ) and $q_{\text {Joule }}=2104.98 \mathrm{~W}$ (and an initial temperature of $T_{0}=140.97^{\circ} \mathrm{C}$ ). The impact was studied for $Z=10 \mathrm{~mm}$ and $Z=20 \mathrm{~mm}$.

The thermal footprints of the sprays impacting on the stainless-steel foil, acquired by the thermographic camera were processed using an adapted version of the thermographic camera video processing MATLAB code developed by Pontes [30], which also describes in detail the calibration and post-processing procedures.

The analysis performed here considered a constant temperature across the foil, which is valid for a Biot number $B i=h d / k_{s}<<1$ [31], where $h$ is the heat transfer coefficient, $d$ is the foil thickness and $k_{S}$ is the thermal conductivity of the foil. Such a condition is met in the present study, since $\delta=O\left(10^{-5}\right) \mathrm{m}, k_{s}=O(101) \mathrm{W} /(\mathrm{m} \cdot \mathrm{K})$ and $h_{l}=O\left(10^{3}\right) \mathrm{W}\left(\mathrm{m}^{2} \cdot \mathrm{K}\right)$.

The thermographic videos are used to calculate the dissipated heat flux from the foil, performing pixel energy balances.

\subsubsection{Uncertainty Analysis}

Regarding the equipment, the main uncertainties are associated to the $\mathrm{K}$ thermocouple readings $\left( \pm 0.03{ }^{\circ} \mathrm{C}\right)$, to the analogue pressure gauge $( \pm 1 \mathrm{psi})$, to the FLUKE 123 SCOPEMETER multimeter $( \pm 1 \mathrm{mv})$ and the current gauge of the HP 6274B DC power supply $( \pm 0.5 \mathrm{~A})$. The atomizer position adjustment knobs have an associated uncertainty of $\pm 0.5 \mathrm{~mm}$.

The dissipated heat flux $q^{\prime \prime}$ diss is determined from a pixel energy balance. The uncertainty of the dissipated heat flux $q^{\prime \prime}$ diss, as a multi-non-correlated-variable function, as proposed by [32], can be higher than $28 \%$. However, this estimation was performed admitting that the temperature in one pixel at a given instant is not correlated with the temperatures of neighbor pixels, nor with the temperature in the previous instant, neither with the input current. This cannot actually happen, and the values are expected to have high positive correlation. Hence, the upper bounds of the uncertainties and the real values are expected to be much lower. 


\section{Results and Discussion on Nanoparticles Addition}

\subsection{Effect of the Nanoparticles in the Nanofluids Thermophysical Properties}

Table 1 shows a very mild effect of adding the nanoparticles on the thermophysical properties of the nanofluids. Indeed, one may notice a slight trend for the specific heat capacity to decrease with the addition of the nanoparticles, while the thermal conductivity mildly increases, as expected, with the increase of the nanoparticles concentration. However, it is worth mentioning that the specific heat of solid alumina and solid silver is one order of magnitude lower than that of the base fluid, while the thermal conductivity is three orders of magnitude higher. Dynamic viscosity is the only property that is significantly altered when the alumina nanoparticles concentration increases up to 1 and $2 \mathrm{wt} \%$. Moreover, the main influence arrives from the use of the surfactant, which mainly decreases the surface tension of water. These trends are in agreement with those previously reported, for instance by Gupta et al. [33] and Sijs et al. [34], as well as by our previous studies, namely Maly et al. [32] and by Figueiredo et al. [26]. The effects on the viscosity and on the surface tension, however, are worth being further investigated since they may alter the atomization mechanisms and consequently the droplet size and velocity distributions in the spray. Such eventual modifications in the spray dynamics may, in turn, affect the impact outcomes as the spray droplets impact on the surface. In fact, as the spray droplets impinge on the surface, several outcomes can be observed depending on the velocity and size of the droplets, thermophysical properties of the fluids and properties of the surface [35]. Hence, the droplets may stick and spread, contributing to the liquid film that will spread on the surface, thus contributing to cooling the surface, they may bounce from the surface or disintegrate into secondary drops. Both outcomes contribute to take liquid mass away from the surface. A more detailed study was reported by some of the authors [36] regarding this topic.

It is very difficult to quantitatively determine the actual outcomes from spray impingement, but there are several semi-empirical models and criteria that can be used to estimate these outcomes [35]. In this context, the following sub-section will focus on how the potential modifications on the fluids surface tension and dynamic viscosity may affect droplet dynamics and try to estimate the impact outcomes. This is important to interpret the heat transfer mechanisms that will be addressed in the final subsection of the results, as one may estimate how much liquid mass from the impinging spray is actually contributing to cool down the surface.

\subsection{Effect of the Nanoparticles in Spray Dynamics}

As aforementioned, the spray characteristics prior to impact are also important to investigate and characterize, as they will allow us to further understand the intricate relation between spray dynamics and the heat transfer processes at spray cooling.

Here, the results presented consist of the basic quantities useful to show elementary effects and used in the empirical models for predicting the outcome of impact. In this sense, most models consider the average size $-d_{10}[\mu \mathrm{m}]$ —and velocity $-\langle u\rangle[\mathrm{m} / \mathrm{s}]$, the span, the Reynolds and the Weber number of impinging primary droplets as shown in Figure 3. It is worth mentioning that the Reynolds number is defined as $R e=r_{l} d_{10}\langle u\rangle / m_{l}$, while the Weber number is defined as $W e=r_{l} d_{10}\langle u\rangle^{2} / s_{l}$.

The results depicted in Figure 3 are consistent with those previously reported in Malý et al. [32] using a similar atomizer, in agreement with the radial position of the liquid sheet. The smaller droplets, which are mostly transported by aerodynamic effects, are mainly located at the central region of the spray in a much lower number. The main difference in the liquid atomization occurs when adding the surfactant, which is an essential element that ensures an adequate mixing of nanoparticles within the liquid. 

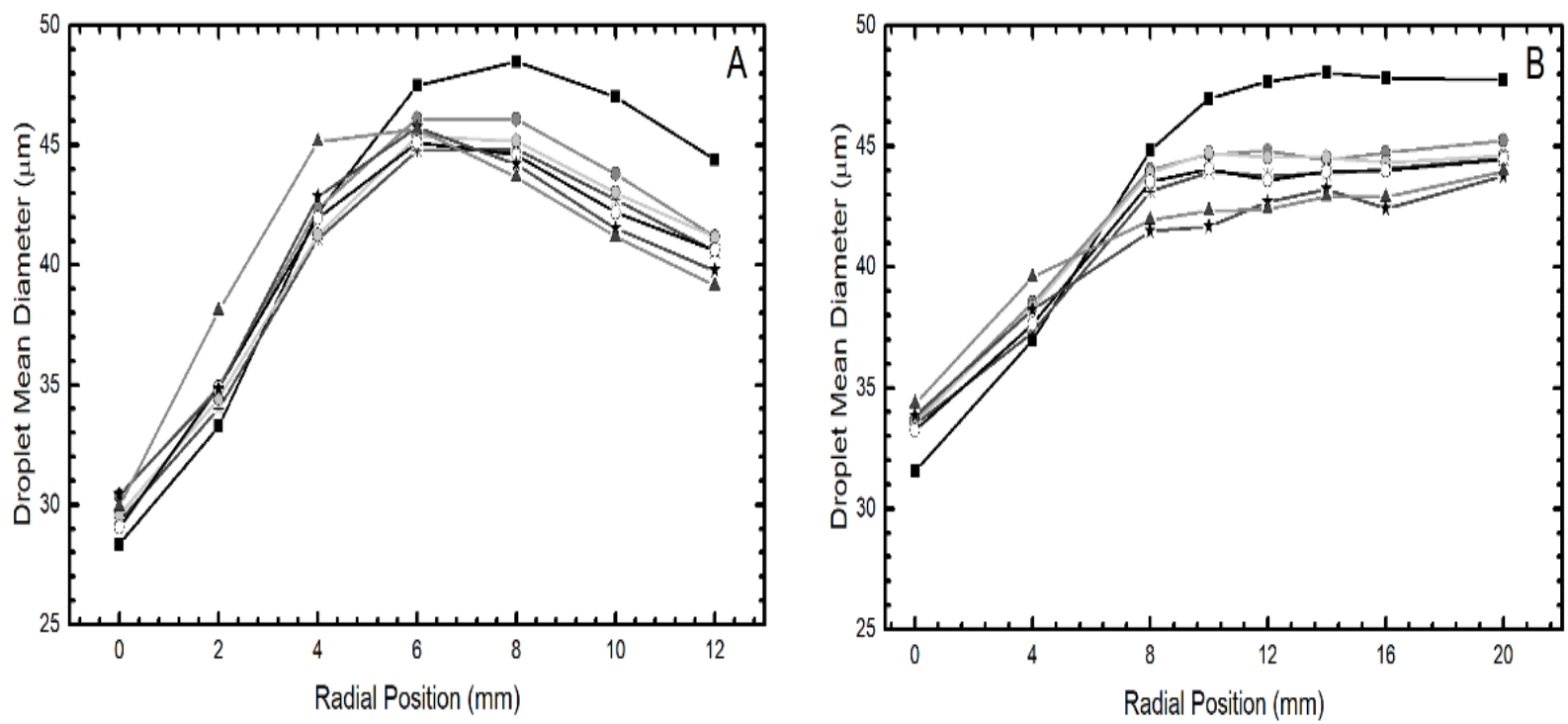

$\longrightarrow$ DI Water — DI Water with Surfactant $\multimap-$ Gold $0.1 \%$ Spherical $\multimap-$ Gold $0.5 \%$ Spherical

$\multimap-$ Gold $1 \%$ Spherical $\multimap$ Gold $0.1 \%$ Cylindrical $\longrightarrow$ Silver $0.5 \%$ Triangular

Figure 3. Average droplet diameter measured with the PDA at different radial positions. (A) corresponds to measurements taken at $Z=10 \mathrm{~mm}$, while $(\mathbf{B})$ corresponds to the measurements taken at $Z=20 \mathrm{~mm}$.

The presence of nanoparticles has a negligible influence over the outcome of atomization, as observed in Figure 3, where the similarity in the shape of the graphs indicate that no major difference is observed for the different values of $Z$. This is a positive result since one of the downsides of using nanoparticles is the undesired modification of the fluid dynamic characteristics of flows due to the increase of the viscosity. This effect is practically unnoticed, particularly in the region where the spray is fully developed, in which surface tension effects mostly dominate the dynamic spray characteristics [32].

An exception is made to the span, characterized as the width or dispersion of the diameter size distribution, defined as:

$$
\text { Span }=\frac{D_{v 0.9}-D_{v 0.1}}{D_{v 0.5}}
$$

where $D_{v 0.9}, D_{v 0.5}$ and $D_{v 0.1}$ are the main fractional volume diameters. It can be a measurement of the symmetry of the dispersion on the particles, since it is in a cone shape manner that the grid performs the measurements. Therefore, the addition of the nanoparticles seems to increase the relative span (Figure 4A,B) around the central coordinates (for $\mathrm{r} \leq 2 \mathrm{~mm}$ ) for some nanofluids, increasing the dispersion of the diameter size distribution. However, the span can provide limited information on the size distributions and looking at the span evaluated at different axial distances from the nozzle, no relation with the nanoparticles material or concentration can be identified.

Droplet outcomes at spray impact will affect the wetted area and the fluid dynamics during spray impingement, which consequently affects the heat transfer processes.

Although a detailed analysis of both spray dynamics and heat transfer during impingement, are addressed in the last subsection, it is worth to evaluate the expected main outcomes (Figure 5), to infer if the spray mass will tend to adhere to the surface or be dispersed in secondary atomization. One can see, qualitatively speaking, that the droplets, resulting from the initial splash or primary atomization, become smaller. As the droplet velocities increase, the surface tension forces do not hold the closed bubble, as it starts to straighten the cone, becoming almost developed. Additionally, at this point, a significant 
part of the analyzed surface area is wetted by the impacting liquid, forming a liquid film due to deposition. If this phenomenon does not occur, then a second atomization happens.
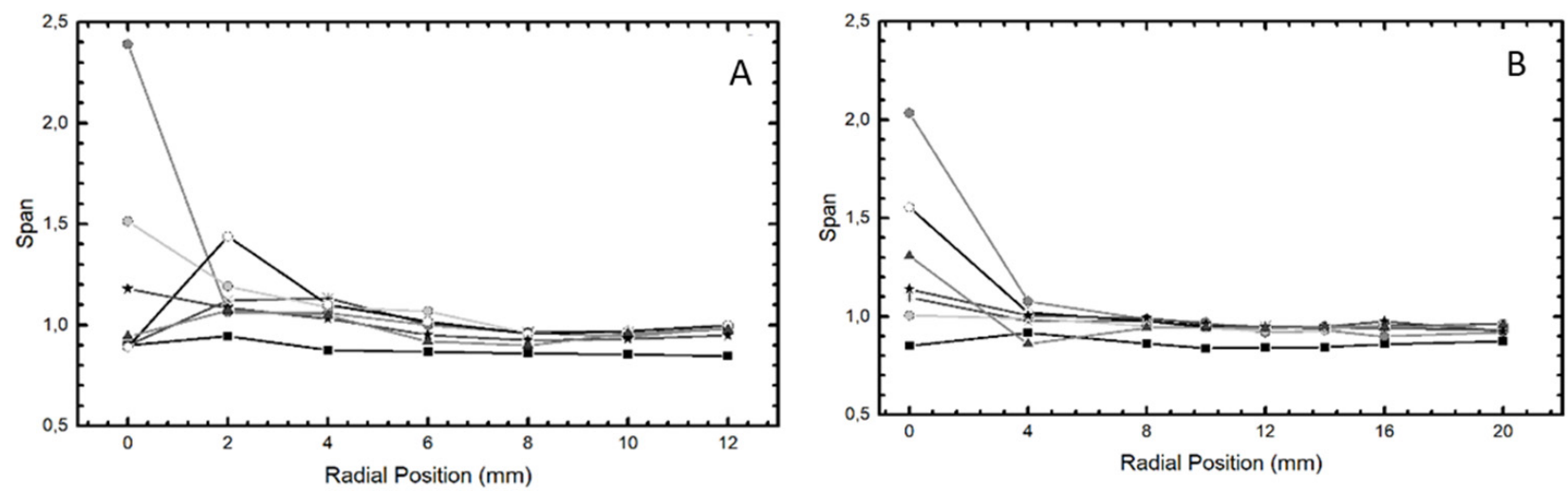

$\rightarrow-$ DI Water - DI Water with Surfactant $\longrightarrow-$ Gold $0.1 \%$ Spherical $\longrightarrow-$ Gold $0.5 \%$ Spherical

$\longrightarrow-$ Gold $1 \%$ Spherical $\longrightarrow$ Gold $0.1 \%$ Cylindrical $\triangle-$ Silver $0.5 \%$ Triangular

Figure 4. Span calculated at different radial positions. (A) corresponds to measurements taken at $Z=10 \mathrm{~mm}$, while (B) corresponds to the measurements taken at $Z=20 \mathrm{~mm}$.
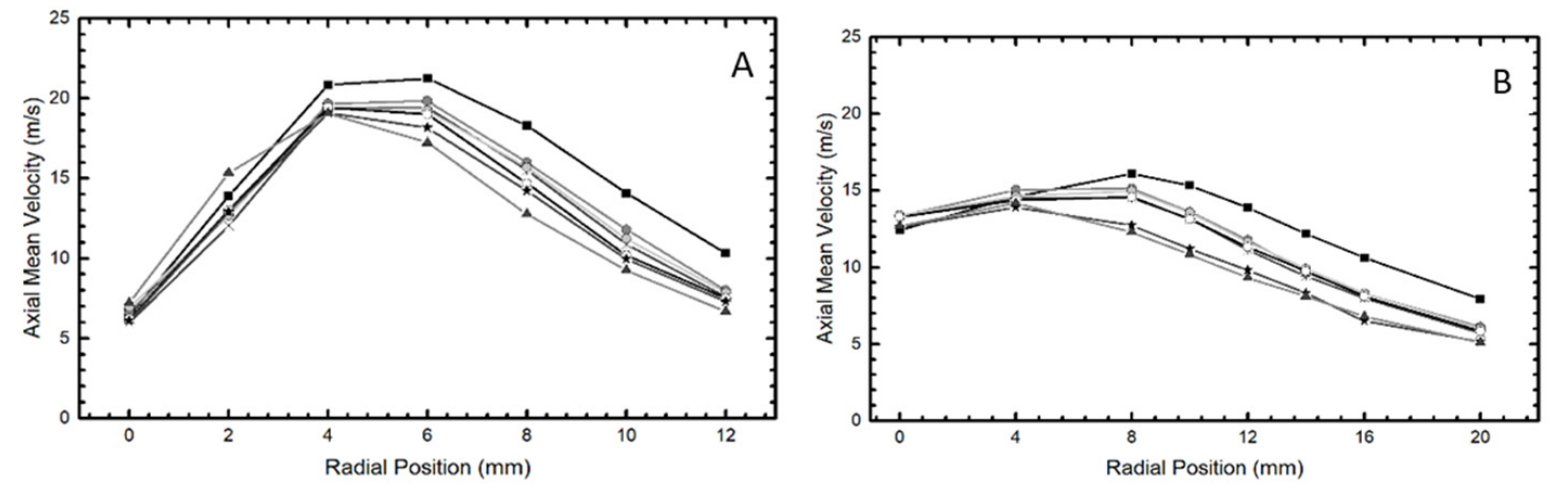

$\rightarrow$ DI Water - DI Water with Surfactant $\longrightarrow-$ Gold $0.1 \%$ Spherical $\longrightarrow-$ Gold $0.5 \%$ Spherical

\section{$\longrightarrow-$ Gold $1 \%$ Spherical $\longrightarrow$ Gold $0.1 \%$ Cylindrical $\longrightarrow-$ Silver $0.5 \%$ Triangular}

Figure 5. Axial mean velocity measured at different radial positions. (A) corresponds to measurements taken at $Z=10 \mathrm{~mm}$, while (B) corresponds to the measurements taken at $Z=20 \mathrm{~mm}$.

Two forces act against the liquid disintegration: surface tension and viscosity. A relative importance of viscous and surface tension forces can be estimated by the ratio of the liquid phase Weber (ratio between the surface tension and inertial forces) and Reynolds (ratio between the inertial and viscous forces) numbers at the nozzle exit (Figure 6) [35]: $\mathrm{We}=\operatorname{Re} \frac{1}{4} w 1=\mathrm{r}$ where $\mathrm{w}$ is the liquid velocity at the exit orifice. It is mainly this ratio that gives the relative importance of the surface tension and the viscous forces. For our case, this ratio shows that regardless of the nanofluid used, the behavior is similar. This suggests the dominance of the surface tension forces over the viscous forces during the spray formation. 

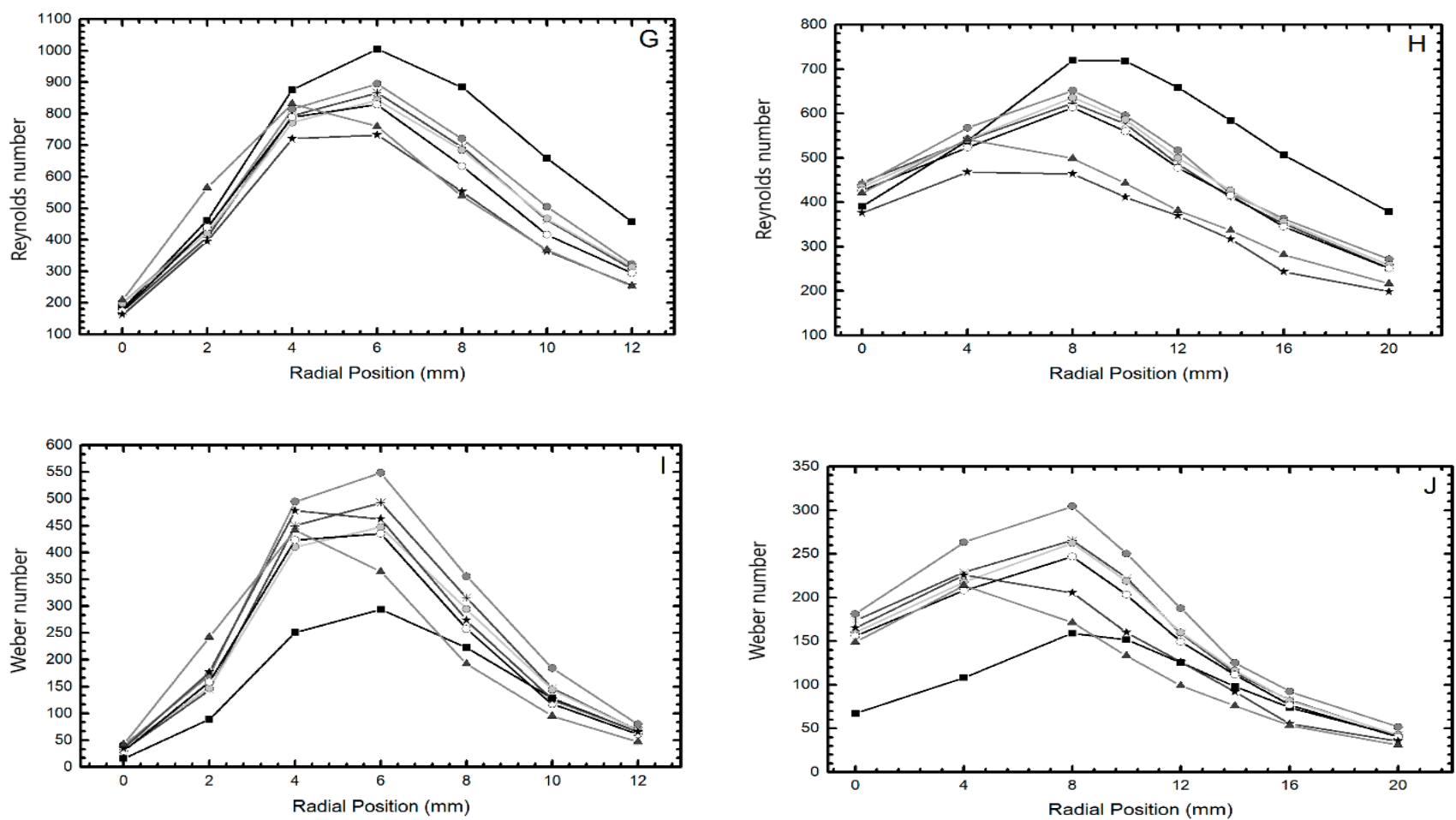

$\longrightarrow$ DI Water — DI Water with Surfactant $-\circ$ Gold $0.1 \%$ Spherical $-\circ$ Gold $0.5 \%$ Spherical

\section{$\multimap-$ Gold $1 \%$ Spherical $₫$ Gold $0.1 \%$ Cylindrical $\_$Silver $0.5 \%$ Triangular}

Figure 6. Mean Reynolds and Weber number determined at different radial positions. $(\mathbf{A}, \mathbf{C})$ corresponds to measurements taken at $Z=10 \mathrm{~mm}$, while $(\mathbf{B}, \mathbf{D})$ corresponds to the measurements taken at $Z=20 \mathrm{~mm}$.

In this context, Figure 7 represents the different threshold criteria for the occurrence of the various droplet impact outcomes according to Bai et al. [36], for a wetted surface, for $Z=10 \mathrm{~mm}$ and $Z=20 \mathrm{~mm}$. Bai et al. [36] criterion is represented by the Ohnesorge number $\mathrm{Oh}=(\mathrm{We})^{1 / 2} / \mathrm{Re}$ as a function of the Reynolds number. For critical ranges of the Ohnesorge number, it is possible to define the threshold regions for each possible impact outcome. At the center line of the spray, $r^{*}=r / r_{\max }=0$ (where $\mathrm{r}_{\max }$ is the maximum radius coordinate considered for each $Z$ ), differences between $Z=10 \mathrm{~mm}$ and $Z=20 \mathrm{~mm}$ are visible. At $Z=10 \mathrm{~mm}$, spread is the predominant outcome. At $Z=20 \mathrm{~mm}$, due to loss in normal momentum, the outcomes extend to the stick region. Moving to the limits of the spray, at $r^{*}=1$, the bimodal flow that is also dominated by low velocity droplets, transported by the vortex structure formed at the wall, induce the dominance of stick for both heights.

It is now important to emphasize that these criteria are just estimates for the outcome of impingement in a wall. In this case the data were collected from a free spray structure that would obviously differ from another with wall impingement. This is also outlined in Panão [37] and in Labergue et al. [38], who also state that these predictions (based on a free spray) overestimate the occurrence of the spreading mechanism.

However, regarding the effect of adding the nanoparticles, even considering the difference in the physical properties of the nanofluids studied here, there are no observable changes when it comes to the impingement outcome, within the range of concentrations considered here. This could, again, be pointed out as a good indicator that spray dynamics are unaffected by their presence in the base liquid. At $r^{*}=0.5$, splash and spread are the dominant mechanisms, linked with high axial velocities and larger droplet diameters. Another relevant factor for these results at $r^{*}=0.5$ is that these droplets would hypothetically collide with the surface with an angle, thus promoting the formation of secondary droplets. 

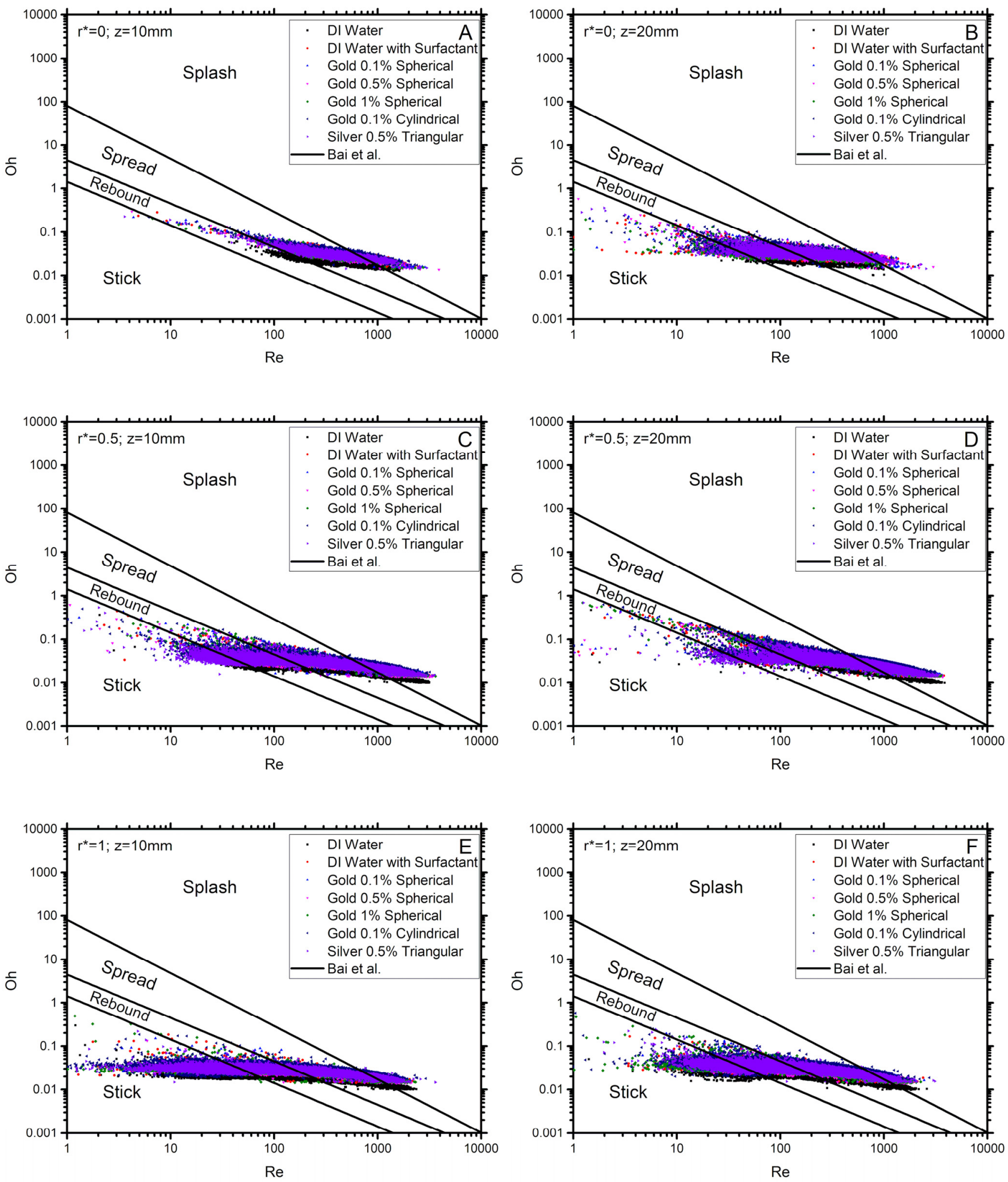

Figure 7. Prediction of the impact outcomes resulting from the spray used here, according to the criteria defined by Bai et al. [36]. (A,B)—average droplet diameter, (C,D)—span, (E,F)—Axial mean velocity.

Finally, it should be noted, from this analysis, that the majority of the droplets impacting the surface will stick and spread on the surface thus contributing to heat flux removal. The presence of the nanoparticles does not alter this trend and does not promote the occurrence of disintegration. 


\subsection{Heat Transfer Mechanisms on Spray Impingement}

\subsubsection{Water Spray}

Water spray is first taken as a reference to characterize the hydrodynamic and thermal behavior of the spray. In this context, Figure $8 \mathrm{~A}, \mathrm{~B}$ show the time evolution of the foil temperature relative to the fluid temperature $\Delta \mathrm{T}$, for distilled water sprays and an imposed heat flux corresponding to $I=10 \mathrm{~A}$ and $I=15 \mathrm{~A}$, respectively. Figures 5 and 6 show two regimes for $\Delta t>0 \mathrm{~s}$. One is the transient regime were the temperature drastically decreases from the initial foil temperature to values close to the fluid temperature. This regime is followed by a steady-state regime were temperatures no longer change with time. Comparing the curves for $Z=10 \mathrm{~mm}$ and $Z=20 \mathrm{~mm}$ show that for the $Z=20 \mathrm{~mm}$, the temperature decreases and stabilizes slightly faster than for $Z=10 \mathrm{~mm}$. This trend is related to the fact that, by placing the atomizer higher relative to the foil, the spray footprint is larger, thus covering a larger area of the foil, resulting in faster cooling.
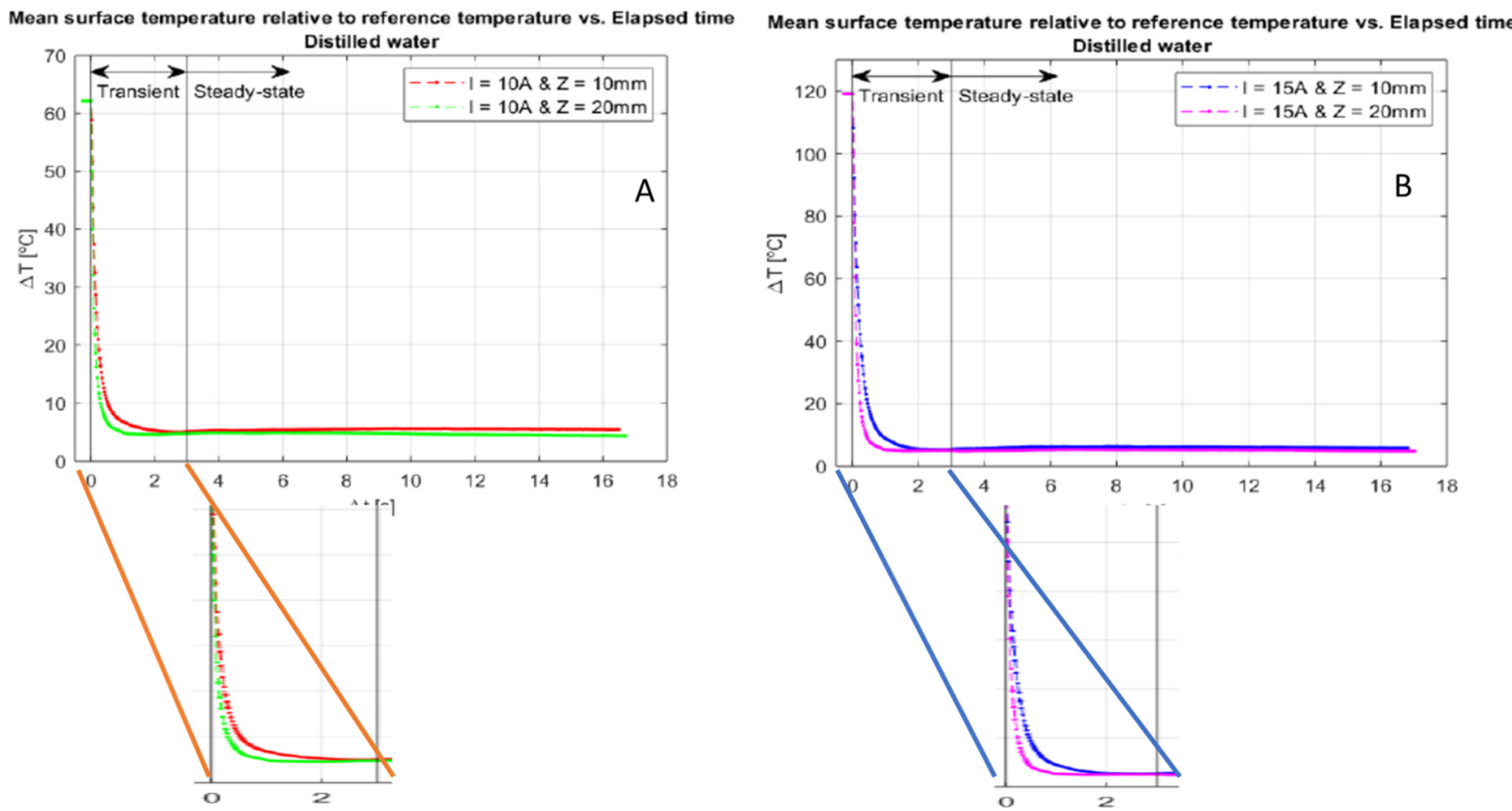

Figure 8. Temporal evolution of the stainless-steel foil temperature relative to fluid reference temperature DT during the impact of the water spray on the smooth and heated stainless-steel foil. The imposed current on the foil is $I=10 \mathrm{~A}$ (A) and $I=15 \mathrm{~A}(\mathbf{B})$.

Figure 9A,B show the temporal evolution of the dissipated heat flux $q^{\prime \prime}$ diss, for distilled water sprays and working conditions with $I=10 \mathrm{~A}$ and $I=15 \mathrm{~A}$, respectively. Similarly to what was observed for $\Delta \mathrm{T}$, the dissipated heat flux plots also show two different regimes for $\Delta \mathrm{T}>0 \mathrm{~s}$. In this case, the transient regime is characterized by a spike in the dissipated heat flux, which then decreases. This regime is followed by the steady-state regime where, again no variations in the dissipated heat flux are verified. The maximum dissipated heat flux is higher for the $Z=20 \mathrm{~mm}$ conditions when compared to the $Z=10 \mathrm{~mm}$ conditions. This is a result of the sharper decrease in temperatures, as observed in Figures 7 and 8 .

\subsubsection{Effect of Adding the Surfactant CTAB}

The values of the heat flux $q^{\prime \prime}$ diss and heat transfer coefficient $h$ in the different working conditions are underlined for water and base fluid, respectively, in Figure 10a,b. The plots show that adding CTAB results in an increase of dissipated heat flux, of about $1.3 \%$ for $Z=10 \mathrm{~mm}$ and of $0.35 \%$ for $Z=20 \mathrm{~mm}$. Furthermore, when comparing the relative mean 
temperature $\Delta \mathrm{T}$, it increases with $\mathrm{CTAB}$ for all situations, except for the maximum working conditions $(I=15 \mathrm{~A}$ and $Z=20 \mathrm{~mm})$. The maximum increase occurs when $I=15 \mathrm{~A}$ and $Z=10 \mathrm{~mm}$ and is of approximately $6.9 \%$. Finally, due to the temperature difference, the heat transfer coefficient decreases with the addition of CTAB, except for the maximum working conditions, where an increase of $2.7 \%$ is verified (Figure $10 \mathrm{~b}$ ). The maximum decrease occurs for $I=15 \mathrm{~A}$ and $Z=10 \mathrm{~mm}$ and is of approximately $5.1 \%$. The observed lower heat transfer coefficients $\left(h=q^{\prime \prime}{ }_{\text {diss }} / \Delta \mathrm{T}\right)$ that are related to the higher temperature profiles obtained with the addition of CTAB may be related with the increased wettability, which enhances the flow of fluid over the foil. Therefore, the liquid film is less thick which reduces the thermal performance. Contrarily to what is observed for the other conditions, when $I=15 \mathrm{~A}$ and $Z=20 \mathrm{~mm}$, the heat transfer coefficient increases with the addition of CTAB. This is a result of the superposition of the radial temperature profiles of water and water with CTAB fluids, for this specific working condition, and slightly higher dissipated heat flux of CTAB fluid relative to water. This phenomenon may be explained due to increased wettability with the addition of CTAB, as predominant factor for this experimental condition.
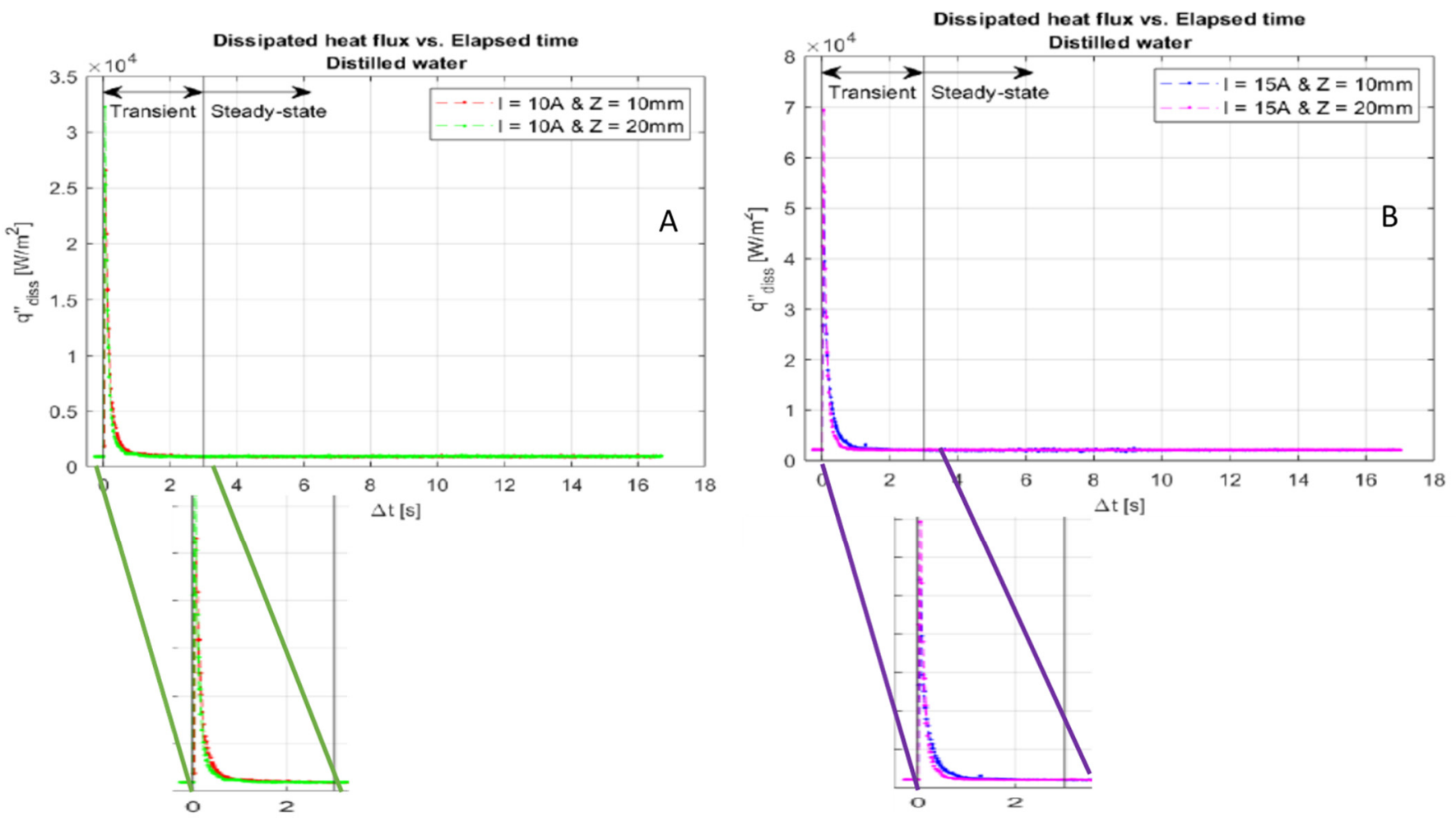

Figure 9. Temporal evolution of the dissipated heat flux $q^{\prime \prime}$ diss during the impact of a water spray on the smooth and heated stainless-steel foil, for an imposed current of $I=10 \mathrm{~A}(\mathbf{A})$; and of $I=15 \mathrm{~A}(\mathbf{B})$.

\subsubsection{Effect of Nanoparticles Concentration (Alumina Nanofluids)}

To explore the effect of nanoparticles concentration, the base fluid (water $+0.05 \mathrm{wt} \%$ $\mathrm{CTAB}$ ) is compared to the alumina nanofluids for concentrations ranging between $0.5,1$ and $2 \%(\mathrm{~m} / \mathrm{m})$.

The dissipated heat flux and heat transfer coefficients for the alumina nanofluids are plotted for the different working conditions, respectively, in Figure 11a,b.

The figure does not allow identifying any monotone variation of the dissipated heat flux $q^{\prime \prime}$ diss with the nanoparticles concentration. For $Z=20 \mathrm{~mm}$ conditions, the maximum $q^{\prime \prime}$ diss is observed, for the concentration $1 \%(\mathrm{~m} / \mathrm{m})$. For the $Z=10 \mathrm{~mm}$ and $I=10 \mathrm{~mm}$, the dissipated heat flux increases with the increase of nanoparticle concentration, whereas, 
for the maximum conditions $(Z=20 \mathrm{~mm}$ and $I=15 \mathrm{~mm})$, the opposite trend is observed, i.e., $q$ " diss decreases as the nanoparticles concentration increases. To better visualize the variation of the heat transfer coefficient with the alumina nanoparticles concentration, Figure 12a-d show the waterfall charts for each working condition. Green bars correspond to positive variations and red bars are negative variations. The blue bar at $0 \%(\mathrm{~m} / \mathrm{m})$ alumina represents the base fluid.

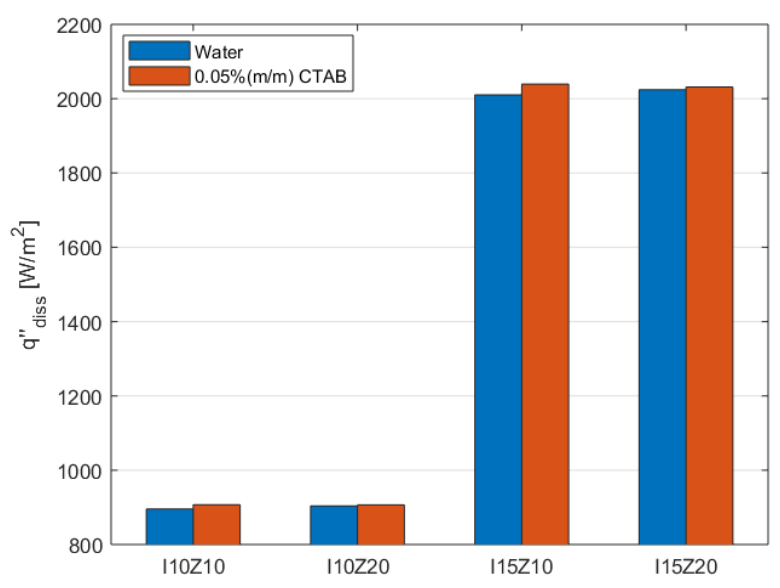

(a)

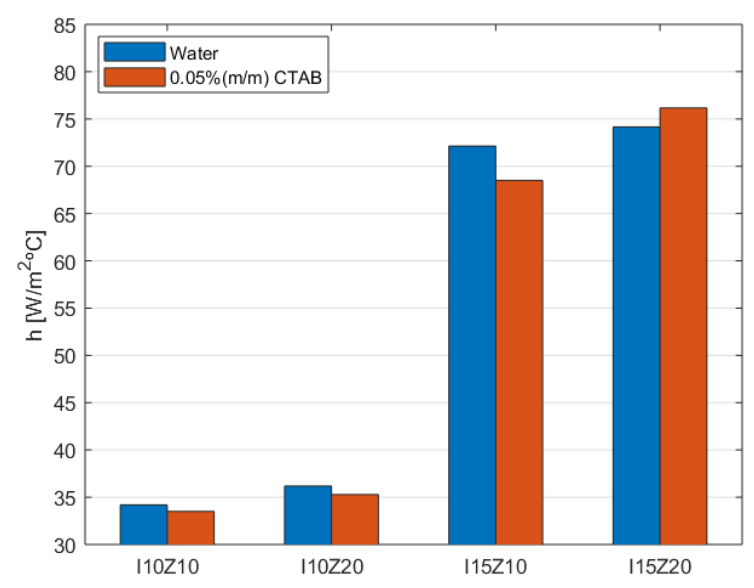

(b)

Figure 10. (a) Dissipated heat flux and (b) heat transfer coefficients for water and base fluid sprays impacting on the smooth and heated stainless-steel foil, for the different working conditions. In the plots, I10Z10 stands for an imposed current on the foil of $10 \mathrm{~A}$ and an impact height of $Z=10 \mathrm{~mm}$. I10Z20 represents the condition of $10 \mathrm{~A}$ of imposed current and an impact height of $Z=20 \mathrm{~mm}$. I15Z10 stands for an imposed current on the foil of $15 \mathrm{~A}$ and an impact height of $Z=10 \mathrm{~mm}$. I15Z20 stands for an imposed current on the foil of $15 \mathrm{~A}$ and an impact height of $Z=20 \mathrm{~mm}$.

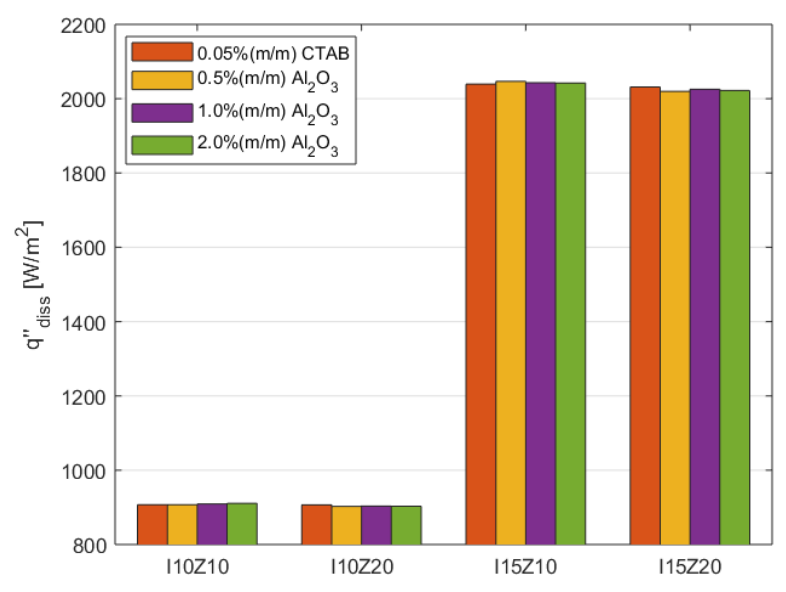

(a)

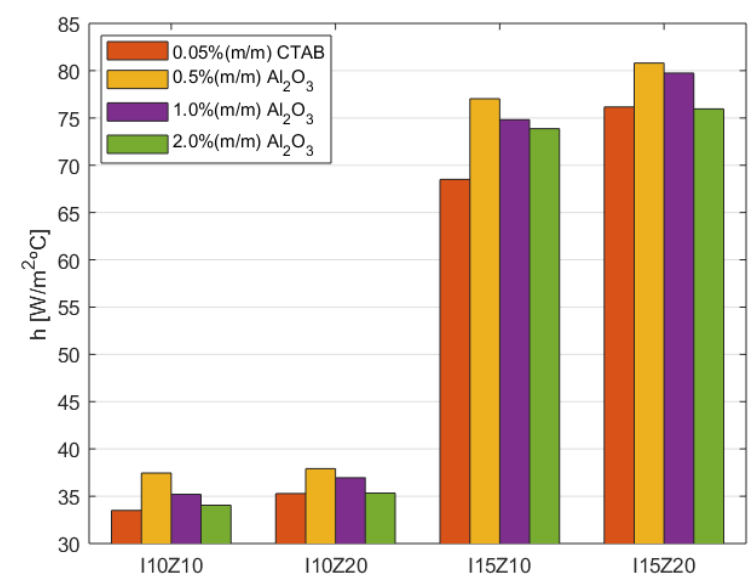

(b)

Figure 11. (a) Dissipated heat flux and (b) heat transfer coefficients for alumina nanofluids impacting on the smooth and heated stainless-steel foil. The base fluid is water + CTAB is also used as a reference. In the plots, I10Z10 stands for an imposed current on the foil of $10 \mathrm{~A}$ and an impact height of $Z=10 \mathrm{~mm}$. I10Z20 represents the condition of $10 \mathrm{~A}$ of imposed current and an impact height of $Z=20 \mathrm{~mm}$. I15Z10 stands for an imposed current on the foil of $15 \mathrm{~A}$ and an impact height of $Z=10 \mathrm{~mm}$. I15Z20 stands for an imposed current on the foil of $15 \mathrm{~A}$ and an impact height of $Z=20 \mathrm{~mm}$. 


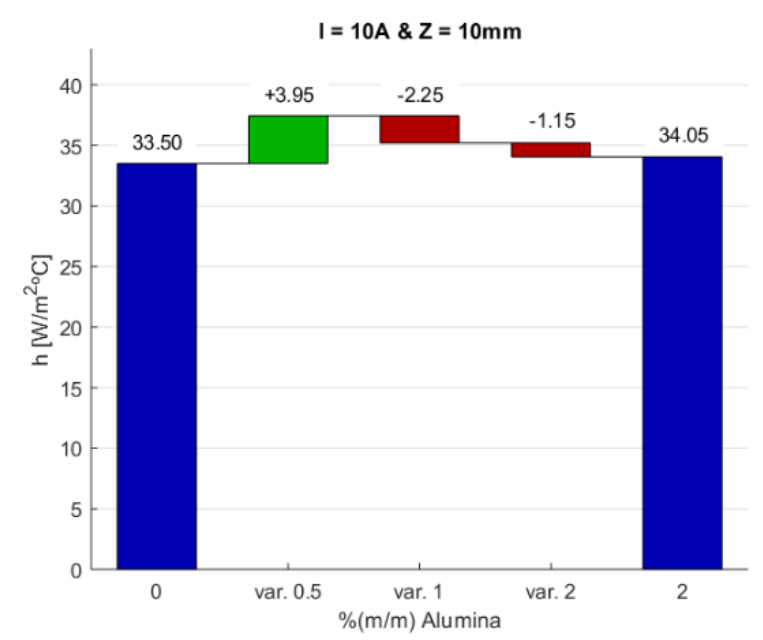

(a) Imposed current of $\mathrm{I}=10 \mathrm{~A}$ and nozzle at $\mathrm{Z}=10 \mathrm{~mm}$

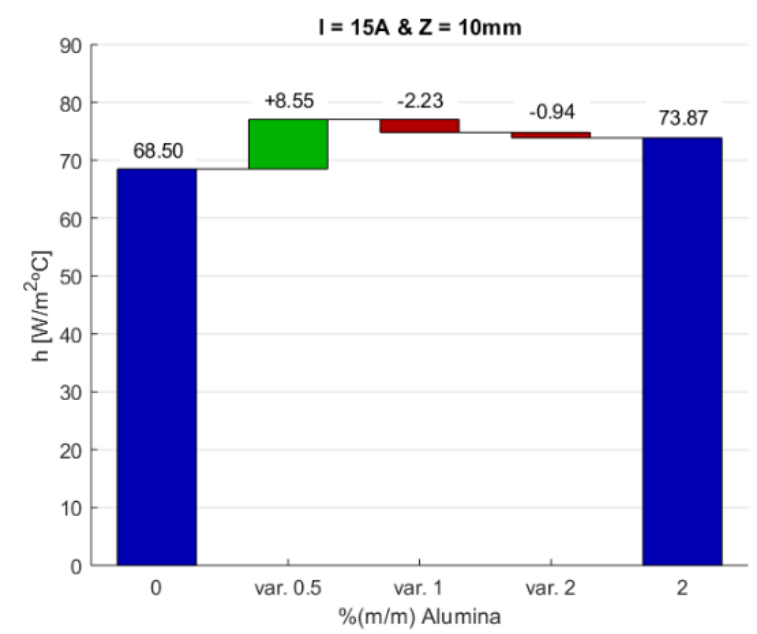

(c) Imposed current of $\mathrm{I}=15 \mathrm{~A}$ and nozzle at $\mathrm{Z}=10 \mathrm{~mm}$

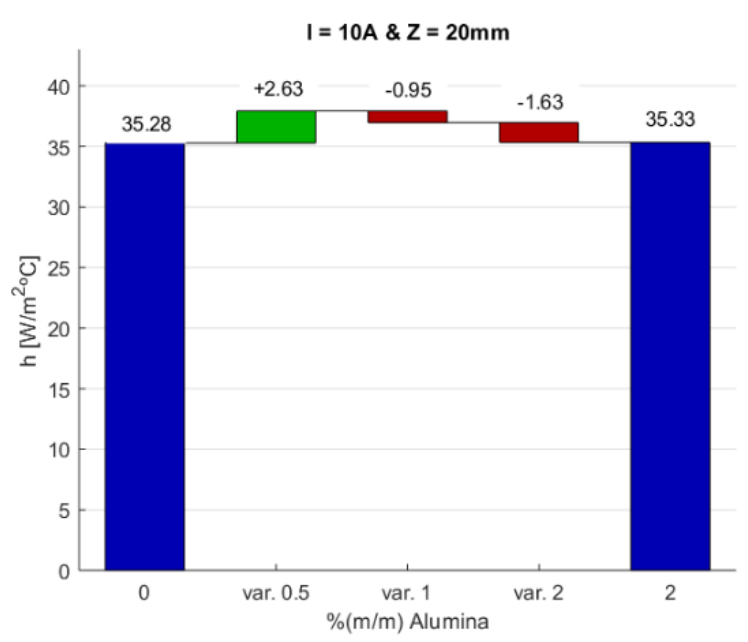

(b) Imposed current of I = $10 \mathrm{~A}$ and nozzle at $\mathrm{Z}=20 \mathrm{~mm}$

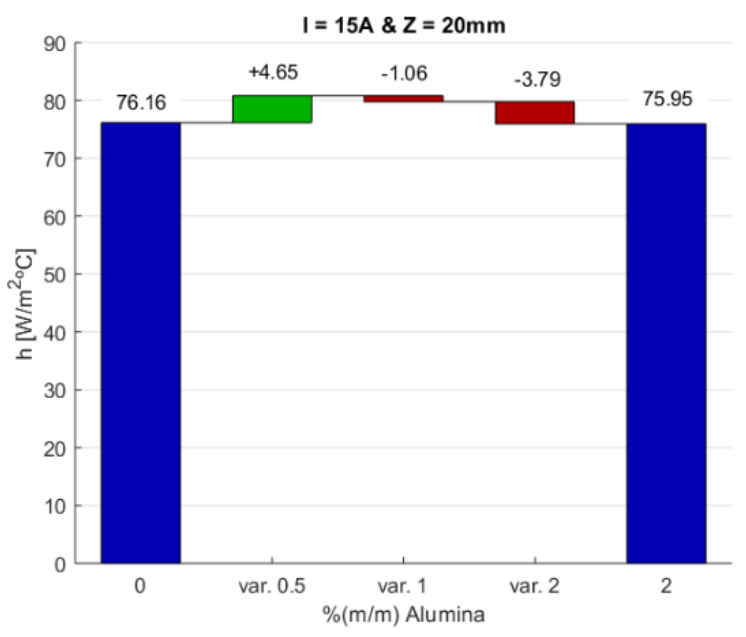

(d) Imposed current of I = 15 A and nozzle at Z = 20 mm

Figure 12. Effect of (alumina) nanoparticles concentration in the heat transfer coefficient waterfall chart for a spray impacting onto a smooth, heated stainless-steel surface. (a) $I=10 \mathrm{~A}$ and $Z=10 \mathrm{~mm}$, (b) $I=10 \mathrm{~A}$ and $Z=20 \mathrm{~mm}$, (c) $I=15 \mathrm{~A}$ and $Z=10 \mathrm{~mm}$ and $(\mathbf{d}) I=15 \mathrm{~A}$ and $Z=20 \mathrm{~mm}$. Left blue bars are the heat transfer coefficient of the base fluid and the right blue bars are the heat transfer coefficients of the alumina $2 \%(\mathrm{~m} / \mathrm{m})$ nanofluid.

Figure 12 shows that, from the base fluid to the alumina nanofluid with $0.5 \%(\mathrm{~m} / \mathrm{m})$ the heat transfer coefficient $h$ increases by $3.95,8.55,2.63$ and $4.65 \mathrm{~W} / \mathrm{m}^{2}{ }^{\circ} \mathrm{C}$ for $\mathrm{I}=10 \mathrm{~A}$ and $Z=10 \mathrm{~mm}$ (Figure 12a), I = $15 \mathrm{~A}$ and $\mathrm{Z}=10 \mathrm{~mm}$ (Figure 12c), I=10 A and $\mathrm{Z}=20 \mathrm{~mm}$ (Figure $12 \mathrm{~b}$ ), and $\mathrm{I}=15 \mathrm{~A}$ and $\mathrm{Z}=20 \mathrm{~mm}$ (Figure $12 \mathrm{~d}$ ), respectively. These values correspond to increase in $h$ of approximately $12 \%$ for $Z=10 \mathrm{~mm}$ conditions and $6 \%$ for $Z=20 \mathrm{~mm}$ conditions. With the increase of alumina content, $h$ tends to decrease and for $Z=20 \mathrm{~mm}$. The heat transfer coefficient for alumina $2 \%(\mathrm{~m} / \mathrm{m})$ is very close to that of the base fluid. Moreover, for $Z=10 \mathrm{~mm}$, the decrease in $h$ from an alumina concentration of $0.5 \%$ to $1 \%$ is twice that obtained from $1 \%$ to $2 \%$. On the other hand, for $Z=20 \mathrm{~mm}$, the decrease in $h$ is higher from $1 \%$ to $2 \%$ than from $0.5 \%$ to $1 \%$. As a consequence of the correlations verified for $\Delta T$ and given the fact that $h$ is inversely proportional to $\Delta T$, a strong negative correlation of $h$ is observed with the thermal conductivity (from $-91.0 \%$ to $-99.9 \%$ ) and a strong positive correlation is obtained with the specific heat capacity (from $84.5 \%$ to $99.9 \%$ ). These correlations are stronger when $Z=20 \mathrm{~mm}$ than when $Z=10 \mathrm{~mm}$.

These changes in heat transfer coefficient may be a result of increased fluid viscosity, which deteriorates fluid motion, and decreased specific heat capacities, thus compromising heat transfer by convection. 


\subsubsection{Effect of Nanoparticles Shape (Silver Nanofluids)}

To analyze the potential effect of the shape of the nanoparticles two different particle shapes, namely triangular and spherical silver nanoparticles were compared. The values of the dissipated heat flux $q^{\prime \prime}$ diss and the heat transfer coefficients $h$ are plotted, respectively, in Figure 13a,b, for the silver nanofluids and for the base fluid. Comparing the results for the dissipated heat flux $q^{\prime \prime}$ diss it is clear that $q^{\prime \prime}$ diss is higher for the silver nanofluids, with respect to the base fluid, for $I=10 \mathrm{~A}$, but decreases when compared to the base fluid when $I=15 \mathrm{~A}$.

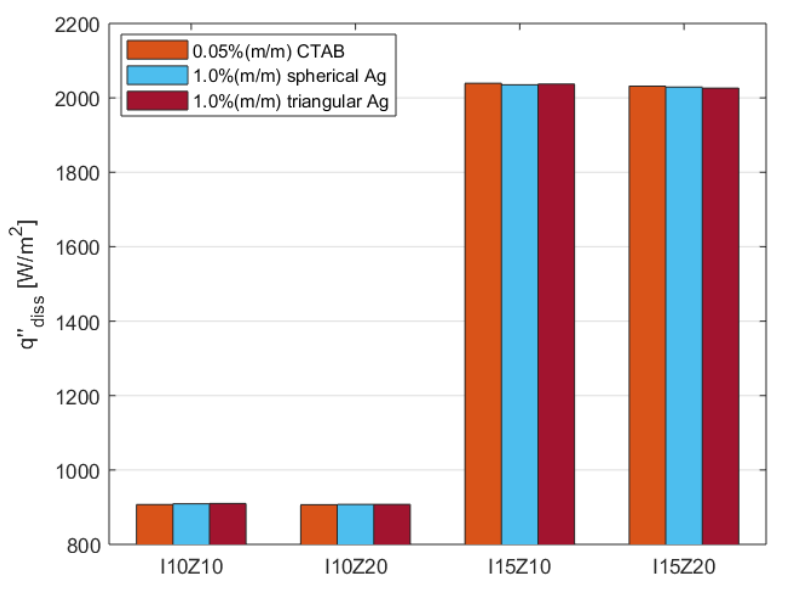

(a) Dissipated heat flux $q^{\prime \prime}$ diss

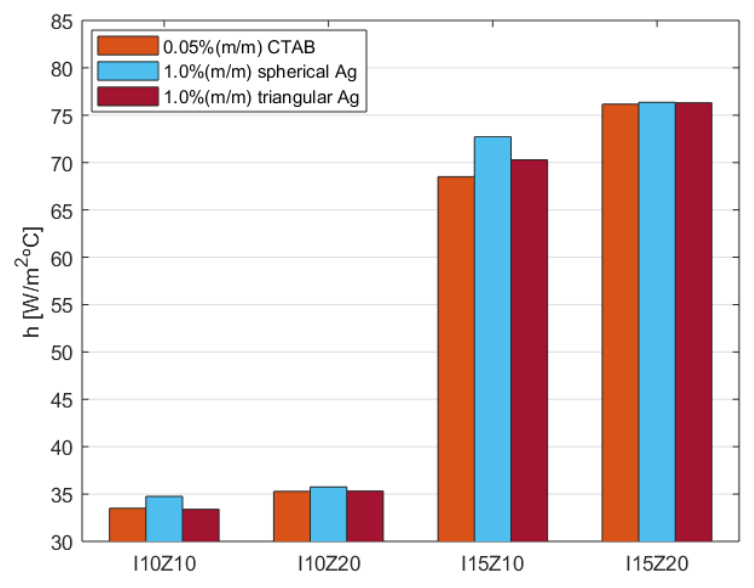

(b) Heat transfer coefficient $\mathrm{h}$

Figure 13. Effect of the shape of the nanoparticles in: (a) Dissipated heat flux and (b) heat transfer coefficients for silver nanofluids impacting on the smooth and heated stainless-steel foil. The base fluid is water + CTAB is also used as a reference. In the plots, I10Z10 stands for an imposed current on the foil of $10 \mathrm{~A}$ and an impact height of $Z=10 \mathrm{~mm}$. I10Z20 represents the condition of $10 \mathrm{~A}$ of imposed current and an impact height of $Z=20 \mathrm{~mm}$. I15Z10 stands for an imposed current on the foil of $15 \mathrm{~A}$ and an impact height of $Z=10 \mathrm{~mm}$. I15Z20 stands for an imposed current on the foil of $15 \mathrm{~A}$ and an impact height of $Z=20 \mathrm{~mm}$.

Figure 13 further indicates that the nanofluid using the spherical silver particles reaches the highest heat transfer coefficients. This trend occurs for all the studied conditions although is more obvious for $Z=10 \mathrm{~mm}$, than for $Z=20 \mathrm{~mm}$. As for the $Z=10 \mathrm{~mm}$, the droplet velocities are higher, thus viscosity plays a more important role, and as the triangular nanofluid has 50\% higher dynamic viscosity than the spherical nanofluid the heat transfer by convection is much more affected.

\section{Conclusions}

The present study addresses the evaluation of nanoparticles concentration and shape in the thermal properties of the nanofluids and in the consequent potential improve in the heat transfer for spray cooling applications. The detailed characterization of spray impingement on a smooth, heated surface was performed and the geometry of the nanoparticles does not seem as important as the geometry of the shape of the atomization. Particular emphasis is given to nanofluid sprays and their potential to enhance the heat transfer mechanisms. The base fluid considered is distilled water with added surfactant cetyltrimethylammonium bromide (CTAB), which decreases the surface tension of the solutions, promoting an increased trend for the droplets to splash. Alumina and silver were the nanoparticles studied in this work, in different weight percentages. Spray dynamics were characterized using Phase Doppler Anemometry, while the thermal footprints of the spray impacting on a heated, smooth stainless-steel foil are evaluated to quantify temperature gradients and heat fluxes transferred during spray impingement. The results show a mild effect of the nanoparticles shape on the silver nanoparticles: higher heat transfer 
coefficients are observed for the silver nanofluids using spherical particles, when compared to the silver nanofluids using triangular nanoparticles. This is an indication that geometry (namely volume and area) are always factors to consider in heat transfer processes. Higher nanoparticles concentration overall leads to the increase in the thermal conductivity and dynamic viscosity of the nanofluids but decreases the heat transfer coefficients. On the other hand, nanofluids specific heat capacity is increased, which results in an enhanced spray cooling capacity.

Author Contributions: Conceptualization, A.S.M., G.M.; methodology, G.M., A.S.M., A.P.C.R.; software, M.S.; validation, A.S.M., G.M.; formal analysis, M.S., A.P.C.R.; investigation, G.M.; resources, A.S.M., G.M., A.L.N.M.; data curation, G.M., A.S.M.; writing-original draft preparation, G.M., A.S.M.; writing-review and editing, G.M., A.S.M., visualization, G.M., A.S.M.; supervision, A.L.N.M.; project administration, A.S.M., G.M.; funding acquisition, G.M., A.S.M. All authors have read and agreed to the published version of the manuscript.

Funding: This research received no external funding. APCR thanks Instituto Superior Técnico for the Scientific Employment contract IST-ID/119/2018.

Institutional Review Board Statement: Not applicable.

Informed Consent Statement: Not applicable.

Data Availability Statement: Not applicable.

Acknowledgments: The authors are grateful to Fundação para a Ciência e Tecnologia (FCT) for partially financing the research under the framework of the project $\mathrm{n}^{\circ} 030171$ financed by LISBOA01-0145-FEDER-030171/PTDC/EME-SIS/30171/2017 and of the project JICAM/0003/2017.

Conflicts of Interest: The authors declare no conflict of interest.

\section{References}

1. Smakulski, P.; Pietrowicz, S. A review of the capabilities of high heat flux removal by porous materials, microchannels and spray cooling techniques. Appl. Therm. Eng. 2016, 112, 636-646. [CrossRef]

2. Liu, N.; Yu, Z.; Zhu, T.; Yin, X.; Zhang, H. Effects of microstructured surface and mixed surfactants on the heat transfer performance of pulsed spray cooling. Int. J. Therm. Sci. 2020, 158, 106530. [CrossRef]

3. Estellé, P.; Cabaleiro, D.; Żyła, G.; Lugo, L.; Murshed, S.M.S. Current trends in surface tension and wetting behavior of nanofluids. Renew. Sustain. Energy Rev. 2018, 94, 931-944. [CrossRef]

4. Choi, S.U.S.; Eastman, J.A. Enhancing Thermal Conductivity of Fluids with Nano- Particles; ASME: New York, NY, USA, 1995.

5. Krishnakumar, T.S.; Sheeba, A.; Mahesh, V.; Prakash, M.J. Heat transfer studies on ethylene glycol/water nanofluid containing $\mathrm{TiO} 2$ nanoparticles. Int. J. Refrig. 2019, 102, 55-61. [CrossRef]

6. Mo, S.; Chen, Y.; Jia, L.; Luo, X. Investigation on crystallization of TiO2-water nanofluids and deionized water. Appl. Energy 2012, 93, 65-70. [CrossRef]

7. Mehralia, M.; Ghatkesar, M.K.; Pecnik, R. Full-spectrum volumetric solar thermal conversion via graphene/silver T hybrid plasmonic nanofluids. Appl. Energy 2018, 224, 103-115. [CrossRef]

8. Alashkar, A.; Gadalla, M. Thermo-economic analysis of an integrated solar power generation system using nanofluids. Appl. Energy 2017, 191, 469-491. [CrossRef]

9. Potenza, M.; Milanese, M.; Colangelo, G.; De Risi, A. Experimental investigation of transparent parabolic trough collector based on gas-phase nanofluid. Appl. Energy 2017, 203, 560-570. [CrossRef]

10. Saxena, V.; Kumar, N.; Saxena, K.V. Multi-objective optimization of modified nanofluid fuel blends at different $\mathrm{T}_{\mathrm{TiO}} \mathrm{H}_{2}$ nanoparticle concentration in diesel engine: Experimental assessment and modeling. Appl. Energy 2019, 248, 330-353. [CrossRef]

11. Kulkarni, D.P.; Das, D.K.; Vajjha, R.V. Application of nanofluids in heating buildings and reducing pollution. Appl. Energy 2009, 86, 2566-2573. [CrossRef]

12. Bansal, A.; Pyrtle, F. Alumina nanofluid for spray cooling enhancement. In Proceedings of the ASME/JSME 2007 Thermal Engineering Heat Transfer Summer Conference, Vancouver, BC, Canada, 8-12 July 2007; ASME: New York, NY, USA, 2007; Volume 1, pp. 797-803.

13. Wang, X.M.; Xu, X.F. Thermal conductivity of nanoparticle-fluid mixture. J. Thermophys. Heat Transf. 1999, 13, 474-480. [CrossRef]

14. Nasiri, A.; Shariaty-Niasar, M.; Rashidi, A.; Amrollahi, A.; Khodafarin, R. Effect of dispersion method on thermal conductivity and stability of nanofluid. Exp. Therm. Fluid Sci. 2011, 35, 717-723. [CrossRef]

15. Mahbubul, I.M.; Elcioglu, E.B.; Saidur, R.; Amalina, M.A. Optimization of ultrasonication period for better dispersion and stability of TiO2-water nanofluid. Ultrason. Sonochem. 2017, 37, 360-367. [CrossRef] 
16. Mansour, R.B.; Galanis, N.; Nguyen, C.T. Effect of uncertainties in physical properties on forced convection heat transfer with nanofluids. Appl. Therm. Eng. 2007, 27, 240-249. [CrossRef]

17. Lyu, Z.; Asadi, A.; Alarifi, I.M.; Ali, V.; Foong, L.K. Thermal and fluid Dynamics performance of MWcnt-Water Nanofluid Based on Thermophysical Properties: An Experimental and theoretical Study. Sci. Rep. 2020, 10, 5185. [CrossRef]

18. Nimdeo, Y.M.; Srivastava, A. Understanding the temperature dependence of thermo-physical properties of nanofluid suspensions using non-intrusive dynamic measurements. Exp. Therm. Fluid Sci. 2018, 94, 109-121. [CrossRef]

19. Dodge, L.; Rhodes, D.J.; Reitz, R. Drop-size measurement techniques for sprays: Comparison of Malvern laser-difraction and aerometrics phase/Doppler. Appl. Opt. 1987, 26, 2144-2154. [CrossRef] [PubMed]

20. Stapleton, K.W.; Finlay, W.H.; Zuberbuhler, P. An in vitro method for determining regional dosage delivered by jet nebulizers. J. Aerosol Med. 1994, 7, 325-344. [CrossRef]

21. Taylor, P.; Dudek, R.; Flaherty, D.; Kaempfe, T. Technical note: Evaluation of two instruments for the measurement of aerosols. J. Aerosol Sci. 1994, 25, 419-423. [CrossRef]

22. Clifford, R.H.; Ishii, I.; Montaser, A.; Meyer, G.A. Dual-beam, light-scattering interferometry for simultaneous measurements of droplet-size and velocity distributions from commonly used nebulizers. Anal. Chem. 1990, 62, 390-394. [CrossRef]

23. Corcoran, T.E.; Hitron, R.; Humphrey, W.; Chigier, N. Optical measurement of nebulizer sprays: A quantitative comparison of diffraction, phase doppler interferometry, and time of flight techniques. J. Aerosol Sci. 2000, 31, 35-50. [CrossRef]

24. Hwang, J.; Bae, C.; Patel, C.; Agarwal, R.A.; Gupta, T.; Kumar Agarwal, A. Investigations on air-fuel mixing and flame characteristics of biodiesel fuels for diesel engine application. Appl. Energy 2017, 206, 1203-1213. [CrossRef]

25. Kay, P.J.; Bowen, P.J.; Gold, M.R.; Sapsford, S.M. Transient fuel spray impingement at atmospheric and elevated ambient conditions. Exp. Fluids 2012, 53, 873-890. [CrossRef]

26. Figueiredo, M.; Marseglia, G.; Moita, A.S.; Panão, M.R.O.; Ribeiro, A.P.C.; Medaglia, C.M.; Moreira, A.L.N. Thermofluid characterization of nanofluid spray cooling combining phase doppler interferometry with high-speed visualization and timeresolved IR thermography. Energies 2020, 13, 5864. [CrossRef]

27. Sundar, L.S.; Sharma, K.V. Thermal conductivity enhancement of nanoparticles in distilled water. Int. J. Nanoparticles $2008,1$. [CrossRef]

28. Qi, W.H.; Wang, M.P. Size and shape dependent lattice parameters of metallic nanoparticles. J. Nanopart. Res. 2005, 7, 51-57. [CrossRef]

29. Machrafi, H. Universal relation between the density and the viscosity of dispersions of nanoparticles and stabilized emulsions. Nanoscale 2020, 12. [CrossRef]

30. Pontes, P.; Cautela, R.; Teodori, E.; Moita, A.S.; Liu, Y.; Moreira, A.L.N.; Nikulin, A.; Del Barrio, E. Effect of pattern geometry on bubble dynamics and heat transfer on biphilic surfaces. Exp. Therm. Fluid Sci. 2020, 115, 110088. [CrossRef]

31. Abu-Nada, E.; Oztop, H.F. Numerical analysis of $\mathrm{Al}_{2} \mathrm{O}_{3}$ /water nanofluids natural convection in a wavy walled cavity. Numer. Heat Transfer Part A App. Int. J. Comput. Methodol. 2011, 59, 403-419. [CrossRef]

32. Malý, M.; Moita, A.S.; Jedelsky, J.; Ribeiro, A.P.C.; Moreira, A.L.N. Effect of nanoparticles concentration on the characteristics of nanofluid sprays for cooling applications. J. Therm. Anal. Calorim. 2019, 135, 3375-3386. [CrossRef]

33. Gupta, M.; Singh, V.; Kumar, R.; Said, Z. A review on thermophysical properties of nanofluids and heat transfer applications. Renew. Sustain. Energy Rev. 2017, 74, 638-670. [CrossRef]

34. Sijs, R.; Kooij, S.; Bonn, D. How surfactants influence the drop size in sprays. arXiv 2019, arXiv:1907.09723v1.

35. Panão, M.R.O. Redefining spray uniformity through an information theory approach. At. Sprays 2016, 26, 1069-1081. [CrossRef]

36. Bai, Y.; Teodori, E.; Moita, A.S.; Pontes, P.; Moura, M.; Moreira, A.L.N.; Li, X.; Liu, Y. Application of bioinspired superhydrophobic surfaces in two-phase heat transfer experiments. J. Bionic Eng. 2017, 14, 506-519.

37. Panão, M.R.O.; Moreira, A.L.N. A real-time assessment of measurement uncertainty in the experimental characterization of sprays. Meas. Sci. Technol. 2008, 19, 095402. [CrossRef]

38. Labergue, A.; Gradeck, M.; Lemoine, F. Comparative study of the cooling of a hot temperature surface using sprays and liquid jets. Int. J. Heat Mass Transf. 2015, 81, 889-890. [CrossRef] 